\title{
Mobile Healthcare Adoption among Patients in a Developing Country Environment: Exploring the Influence of Age and Gender Differences
}

\author{
Khaled M. S. Faqih ${ }^{1} \&$ Mohammed-Issa Riad Mousa Jaradat ${ }^{1}$ \\ ${ }^{1}$ Department of Information Systems, Faculty of Prince Hussein Bin Abdullah for Information Technology, Al \\ al-Bayt University, Mafraq, Jordan \\ Correspondence: Mohammed-Issa Riad Mousa Jaradat, Department of Information Systems, Faculty of Prince \\ Hussein Bin Abdullah for Information Technology, Al al-Bayt University, Mafraq, Jordan. E-mail: \\ mi_jaradat@aabu.edu.jo
}

Received: June 29, 2015

Accepted: August 24, 2015

Online Published: August 25, 2015

doi:10.5539/ibr.v8n9p142

URL: http://dx.doi.org/10.5539/ibr.v8n9p142

\begin{abstract}
This research was motivated by two considerations: (1) Mobile-based technologies have the potential to improve the delivery process of healthcare services, and (2) limited research has been implemented worldwide to focus on patients' perceptions towards the adoption of mobile healthcare, particularly in developing country environment. This research proposes an extended TAM model as a research framework to better understand the adoption process of mobile healthcare among patients. To serve the objectives of this study, a paper questionnaire was employed to collect data. Previously validated set of measurement items were used to develop the survey instrument. The proposed research model was validated using the PLS-SEM approach (WarpPLS 4.0) with a sample of 366 respondents. The results of the current study have provided adequate statistical support for the extended TAM model. With the exception of cost, all external variables incorporated in this model (including perceived ease of use, perceived usefulness, social influence, trust, and security/privacy) are found influential in shaping the patients' perceptions towards the adoption of mobile-healthcare technology. In addition, the current study demonstrates that demographic variables of age and gender have considerable moderating influence on the adoption of mobile technologies in healthcare systems in Jordan. The current research model can serve as a blueprint for future expansion of research in this vital field of study. Theoretical contributions, practical implications and future research directions of the study are also addressed.
\end{abstract}

Keywords: mobile healthcare, TAM model, social influence, trust, security/privacy, cost, age, gender, Jordan

\section{Introduction}

Information technology (IT) has dramatically impacted the way we communicate to the extent that the world has become a small village. Several aspects of our live have been drastically transformed by the emergence of advanced information and communication technologies (ICTs) such as computer, the Internet, and mobile technologies. These technological innovations have the potential to accelerate elemental changes in society and can drive human life to flourish and achieve a higher level of quality in terms of economy, productivity, health, social relations and interactions. Definitely, these innovations have fast developed to become indispensable tools for everyone. The influence of IT has also permeated every shred of business which in effect has pushed businesses to eagerly ride the wave of IT revolution in order to achieve better ways of doing businesses and gaining a competitive edge in today's fast-changing, dynamic and turbulent business environments. However, the intensity of this change does not seem to come to a halt in the near future to say the least. Apparently, one of the areas that have been highly impacted by the phenomenon of IT is healthcare industry, particularly in the developed nations. Without a doubt, many of developed countries have recognized the importance of IT in delivering improved healthcare systems to their peoples. As a result, many healthcare domains in the western countries have been transformed by ICTs. In particular after the inception of the Internet, which has brought about a wealth of opportunities for health sector to grow, evolve and develop.

The current study will define mobile healthcare (m-healthcare) as the use of mobile devices (e.g., mobile phones, smartphones, tablets) and wireless technologies (e.g., Bluetooth, RFID, Wi-Fi, wearable devices, NFC) to deliver health services to enable patients manage their own health more effectively and independently. Indeed, the use of mobile technology in healthcare systems has the prospective to enhance the quality of healthcare deliverables 
and cut considerably the cost of healthcare activities and operations (Chiarini et al., 2013). For example, according to a recent report that EU countries could save as much as 99 billion euros by 2017 if mobile technologies (m-technologies) are effectively reinforced and used in their healthcare systems (Europe, 2013). Indeed, according to the same report that EU healthcare budgets are mostly ( $75 \%$ on average) consumed on caring for chronic diseases which need constant care and several health professionals to handle its associated complex conditions. Further, one of the most favoring characteristics of m-technology is its ability to increase patients' mobility so that they can be accessed and communicated with 24/7. However, the favorable characteristics and unique qualities that $\mathrm{m}$-healthcare technology possesses have not been adequate to encourage individuals to adopt and use the technology. Certainly, irrespective to the fact that $\mathrm{m}$-healthcare has been recently a hot and debating issue for healthcare providers, Mobihealthnews (2014) reported that healthcare systems are still lagging in terms of usage and leverage of m-technology in engaging and better serving patients when compared to other industries. For example, according to Mobihealthnews's report, a survey was launched to investigate the expected future use of mobile in serving healthcare industry by chief information officers (CIOs) at healthcare companies in the US has reported that some $36 \%$ of CIOs had no intention to use mobile for healthcare, while more than $60 \%$ of CIOs at business enterprises and business retailers confirmed that they have already had in place applications and mobile-friendly websites.

Indisputably, m-technology has revolutionized communication process within the healthcare environments and it is becoming more efficient in service delivery, seamlessly effective in improving joint function, cost-effective, adaptive to emergencies, quality-effective, responsive to changes, and overwhelmingly more simplified and streamlined (Mayernik et al., 2010; Trobec \& Stanic, 2011; Gurman et al., 2012; Deloitte, 2014). Admittedly though, IT with its mighty computing capabilities has many miles to travel to achieve a specific satisfaction level in delivering the goods for healthcare systems. This is due to a complexity of issues related to the problematical nature of healthcare systems (Conklin, 2002; Raghupathi \& Tan, 2008; Wälivaara et al., 2011), and these issues are yet to be comprehensively pinpointed and understood. Besides, it is a fact that humans' health is never unchanging. People's health are changing and continuously exacerbated by an increase of new forms of diseases due to some genetically modified foods (Verma et al., 2011), the increase of non-communicable diseases (World Health Day, 2014) and the spread of malignancy, and these health issues and other things can cause changes in healthcare environment that complicate even further the IT performance in delivering better health services.

Many governments of developing countries are facing economic challenges and experiencing lack of appropriate infrastructure to provide adequate healthcare services to its citizens. Indeed, many low-income countries are primarily challenged with budgetary healthcare pressures that strongly impede the development of matured and adequate healthcare systems in such countries (Deloitte, 2014). Nevertheless, how IT provides services to healthcare industry is yet to mature and evolve, particularly in developing countries. Correspondingly, given the huge number of barriers ever present in healthcare environments, achieving an effective m-healthcare ecosystem is not practically possible in the foreseeable future. Apparently, information technology revolution is facing unprecedented challenges in many aspects in its attempt to reform healthcare systems to be able to align patients' needs with available healthcare resources that allow patients to manage their own health problems independently. Therefore, further empirical research along these lines is highly advisable to enable deeper understanding of mobile healthcare innovation, and such research may generate new insights that lead successfully to the development of new strategies to help facilitate the adoption of mobile-based technologies in healthcare from both clinical professionals' and patients' perspectives.

The current empirical analysis is designed to achieve many objectives. First, the usage of m-technologies in healthcare domains is becoming increasingly a widespread phenomenon for the benefit of potentially enhancing the quality of healthcare delivery. Still though, there has been little research conducted for enhancing the adoption of these innovations in healthcare systems, particularly in the context of developing countries. For example, a systematic literature review conducted by Chib et al. (2014) has attributed that the main barriers for the slow uptake of m-healthcare in low-income countries for two reasons: (1) There is no adequate research attention focusing on the theoretical understanding of $\mathrm{m}$-healthcare adoption process in the current literature, and such research may generate measures that can be utilized to make policy decisions and formulate a set of measurement criterion to accelerate the adoption of mobile technology among patients. (2) There is no real evidence demonstrating the existence of scalable and sustainable impact on health indicators by the use of $\mathrm{m}$-technologies. However, despite the fact that mobile penetration in Jordan has approached $156 \%$ by the end of 2013 (The Jordan Times, 2014), Jordan is still lagging behind in the adoption of IT applications in healthcare domains. Meanwhile, empirical studies related to this field of research are almost non-existent in the current literature, particularly investigating the adoption of m-healthcare among health professionals and patients in a 
developing country perspective. One of the rare studies that have tackled m-healthcare domain was conducted by Jaradat and Smadi (2013). They have previously discussed the direct influence of some important factors, including trust, security/privacy, compatibility, social influence, perceived usefulness, and perceived ease of use, on patients' behavioral intentions to adopt and use m-healthcare technology. The researchers concluded that further studies in m-healthcare domain are urgently required to examine additional factors and moderators that may influence the adoption and acceptance of m-healthcare in Jordan (Jaradat \& Smadi, 2013). Indeed, there exists a knowledge gap in literature in the current field of this research. Therefore, the current research is set to close this knowledge gap. Further, this study can be regarded as a step forward in the direction to better understand the users' perceptions to improve the use of m-technologies in healthcare. Second, reviewing current literature shows that the preponderance of empirical analysis conducted to advance our knowledge on consumers perceptions and perspectives towards the adoption of $\mathrm{m}$-technologies in healthcare landscape have been viewed from the viewpoint of clinical professionals. Nevertheless, limited knowledge is documented about the adoption behavior of m-healthcare phenomenon from the viewpoint of patients (Jaradat \& Smadi, 2013; Sun et al., 2013). Indeed, there has been little research conducted from patients' perspective for enhancing the adoption and acceptance of these innovations on healthcare. For example, a literature review carried out by Samhan et al. (2013) on the adoption and usage of m-technologies in supporting patients' needs for better healthcare quality. The study has drawn many conclusions. One of which, and more importantly, irrespective to the fact that m-technologies are quite pervasive worldwide and apparently an exciting tools to serve patients' healthcare requirements, yet this critical field of study is still poorly researched in the MIS literature (Dadgar et al., 2013). This knowledge gap in this field of study needs to be handled. Obviously, the potential benefits of bridging this gap will possibly have real consequences for patients. Therefore, this research aims to fill this gap in literature by exploring the $\mathrm{m}$-technologies adoption by patients in the context of healthcare.

Third, motivated by its simplicity, cost-effectiveness and ease of implementation, the TAM model has remained one of the best choices in adoption of information systems research. However, for this model to further flourish and prosper in enhancing its performance to better gauge the adoption trends in various contexts, Venkatesh and Bala (2008) enthusiastically declared that there is an imperative need to apply and investigate this model in different contexts, domains and settings. Worldwide, the TAM has been much under-utilized to predict the adoption of m-healthcare technology innovation. Correspondingly, the TAM has not been extensively used in $\mathrm{m}$-healthcare domain to gauge the adoption intentions of a specific target audience like patients. Therefore, a knowledge gap exists in literature. Overall, this research intends to contribute mainly to address this knowledge void.

Fourth, researchers and academics have pursued the use of the TAM model over the last three decades in different adoption studies across different domains, and attempting to extend its boundary with domain-specific constructs to accommodate with the characteristics and environment of the new technology in question. However, literature lacks studies that extend the TAM model in the context of m-healthcare. Indeed, these kinds of research studies are absent from current literature. Therefore, the current analysis is intended to extend the TAM model to include variables such as social influence (SI), trust, security/privacy and cost. Generally, this research analysis intends to fill this knowledge gap in current literature.

Fifth, studies in various IT domains have concluded that age differences have been widely recognized to play a decisive and impacting role in the decision-making process of a biometric adoption of information technologies (Venkatesh \& Davis, 2000; Hung et al., 2003; Venkatesh et al., 2003; Chang et al., 2005; Porter \& Donthu, 2006; Zhou et al., 2007; Passyn et al., 2011; Fan \& Miao, 2012; Ansary \& Roushdy, 2013). However, limited attention has been paid to explore the influence of age differences in the adoption of m-healthcare applications. This is, of course, signaling the existence of a knowledge void in the present literature. Therefore, it is critically imperative to better understand the effect of age differences in predicting and motivating the adoption behavior of individuals in $\mathrm{m}$-healthcare domain in a developing country perspective. Indeed, one of the major purposes of the present empirical research is to address this knowledge void in m-healthcare domain.

Finally, in fact, as noticeable from literature that the studies of Gefen and Straub (1997) and Venkatesh et al. (2003) in particular have inspired researchers worldwide to investigate gender effects in a quite number of studies in various IT domains. Undoubtedly, the moderating effects of gender have been statistically confirmed in adoption and acceptance studies of different information technology domains and settings (Lichtenstein \& Williamson, 2006; Zhang, 2009; Hasan, 2010; Riquelme \& Rios, 2010; Van Slyke et al., 2010; Dong \& Zhang, 2011). Apparently, there has been no conclusive evidence to suggest that gender differences always have a pronounced effect in relation to the research conducted in the context of adoption of a new technological innovation (Bigne et al., 2005; Cyr \& Bonannni, 2005; Calisir et al., 2009; Dong \& Zhang, 2011). In the 
meantime, many empirical analyses have demonstrated that gender has little significance in the adoption of information technology (Bigne et al., 2005; Zhou et al., 2007; Lip-Sam \& Hock-Eam, 2011). However, the moderating effects of gender have not largely been investigated in the context of m-healthcare. Indeed, these types of research studies are non-existent in literature. However, given the conflicting nature of the empirical research results reported above in non-healthcare domains and the scarcity of the empirical research in healthcare domains. Therefore, there is an imperative need to examine the influence of gender in studies related to the adoption of m-technologies in healthcare in developed and developing country environments. Apparently, there exists a knowledge gap in understanding the moderating influence of gender in $\mathrm{m}$-healthcare adoption studies. Definitely, one of the major contributions of the current research is to identify the gender moderating effect in relation to m-healthcare adoption. Therefore, this analysis will attempt to fill the knowledge gap in the literature.

The remaining of this study is structured as: Section 2 presents the theoretical background of this research. Section 3 provides the hypothesis development for this research. Section 4 describes the proposed research model followed the research methodology in section 5, which includes sampling, data analysis and results. Section 6 describes the discussion of the results. Finally, section 7 concludes the study with contributions, conclusions, limitations and future research.

\section{Theoretical Background}

\subsection{Technology Acceptance Model (TAM)}

The TAM theory is a validated scientific tool that is commonly used to explore technological innovation acceptance by individuals, it is intended to explain the factors which determine technology adoption, acceptance and use intentions (Davis, 1989). Without a doubt, the TAM model has been extensively applied in almost every domain of computer-based and mobile-based technologies, covering the full spectrum of new and emerging technologies, and proved reliable and successful in explaining the adoption process of these technologies. TAM has also been responsible for popularizing and facilitating the adoption of all types of IT-related technologies among individuals as well as organizations. Indeed, over the last three decades, TAM has maintained its validity and reliability characteristics despite its extensive usage in gauging the adoption of a diversity of technologies in diverse cultural and different social settings for a variety of different users. As a result, the TAM model has over the years gained notable academic acceptance and overwhelming popularity in the adoption of IS/IT technologies. A remarkable refinements and modifications of the primary TAM theory (TAM2, UTAUT, and TAM3) have been proposed since its inception to make it more versatile in attempting to address the adoption of new and emerging technologies. The TAM model theorizes that perceived ease of use (PEOU) and perceived usefulness (PU) are the two most important components that influence individual's behavioral intention (BI) leading to the adoption acceptance and usage of the technology (Davis et al., 1989). Indeed, these conceptual beliefs are the major building blocks of the TAM theory. In the meantime, most TAM-based research studies have established that these beliefs have predominantly prevailed as major determinants of technology adoption and acceptance. Furthermore, these two concepts are characterized by their underlying simplicity in design and implementation in the context of IT/IS adoption studies (Hung \& Chang, 2005).

An explorative review of literature was conducted to analyze the themes and findings of recently published articles employing quantitative research paradigm on the adoption and acceptance of e-health (Li et al., 2013). This literature review has concluded that the TAM model was the most widely used approach for investigating and understanding the people's adoption and acceptance of information technology in healthcare context; such context is characterized by highly nonlinear dynamical complexity, particularly diseases (Leischow et al., 2008). Yet, not many empirical research studies have utilized the TAM theory as a theoretical framework to investigate the adoption of m-technologies in healthcare domains. However, only a few of these studies have extended the structural boundary of the TAM by incorporating new parameters that deem imperative or relevant or to place premiums on particular settings applicable to various healthcare domains. These studies were conducted in order to better comprehend the adoption mechanisms of m-technologies in varying healthcare contexts and settings from consumers' perspectives and perceptions.

\subsection{Healthcare Informatics}

Healthcare environments are very complex interrelated chains of events and in the process of operations, healthcare systems are composed of a complicated system of triggers (Conklin, 2002). There are also many different aspects and issues associated with healthcare systems that complicate its methods of operations (Raghupathi \& Tan, 2008; Wälivaara et al., 2011). In addition, healthcare incorporates a variety of influencing players whose boundaries are overlapping and each one has certain perspectives with varying degree of uniqueness (Chandra \& Skinner, 2012; Cresswell \& Sheikh, 2012). However, to ensure maximum efficiency of 
healthcare operations, the mighty information technology is the force that possesses the potentials to smooth and streamline the complex flow of information among health care's associated activities and operations. In order to achieve this objective, computer-mediated technologies have pushed their boundaries into interesting and exciting territories of health realm and this has signaled the birth of a new healthcare format named electronic-healthcare (or more commonly e-healthcare).

The e-healthcare concept has the potential to assist health providers in meeting evolving clinical demand and guarantee timely access to patient information that enables them to make swift clinical decisions that may help save patient's life. Indeed, the e-healthcare phenomenon has already established its presence in healthcare sphere and has largely impacted healthcare systems to better achieve quality deliverables and outcomes to all users and parties involved in healthcare systems (Kaplan, 2008; Mayernik et al., 2010; Trobec \& Stanic, 2011; Hill et al., 2012). Indeed, the new innovation of e-technologies has potentially achieved greater connectivity at the point of care where healthcare providers, healthcare professionals, and patients can leverage the best information and knowledge for better informing decision-making in the delivery of cost-effective healthcare (Gurman et al., 2012).

Almost all countries, rich and poor, are working hard to acquire the necessary infrastructure, knowledge, and related technologies to improve their healthcare delivery systems. The key challenge facing the world today is the growing demand on healthcare services due to the appearance of a number of new forms of diseases and the global aging phenomenon of world's population, particularly in developed countries, which occurs rapidly at significantly higher rates than the availability of healthcare resources and healthcare services provision (Lee \& Mason, 2011). Indeed, many low-income countries are primarily challenged with budgetary healthcare pressures that impede the development of matured healthcare systems in these countries (Basu et al., 2012). Therefore, the only influential mean that countries can do is the pursuance of the power of IT, particularly m-technologies, to achieve an acceptable level of healthcare provision at reduced cost (Raghupathi \& Tan, 2008; Wälivaara et al., 2011).

The birth of m-technology revolution and its explosive growth have helped developing nations overcome the lack of infrastructure or achieving what is called by scholars ' $\mathrm{m}$-technology leapfrogging', which has enabled developing economies to skip the fixed-line technology (Napoli \& Obar, 2013). Indeed, mobile telephony does not involve the same degree of infrastructure as previous forms of digital technologies such as the Internet. The potentials for emerging m-technology has unleashed for the emergence of a novel healthcare domain named $\mathrm{m}$-healthcare. This new domain has captured the intention of healthcare providers and clinical professionals due to its potentially expected impact on the community's healthcare, particularly patients with long-term conditions. The term m-healthcare was first coined by Professor Robert Istepanian of Kingston University in London in 2003. It refers to the utilization of mobile communications and network technologies in the area of healthcare services (Istepanian et al., 2006). Recently, a more expanded definition has emerged, whereas m-healthcare is referred to as the usage of mobile communications technology and devices to enhance access to healthcare information, improve distribution of routine and emergency health services and provide diagnostic services (Market Research Moz, 2013). The strength of m-healthcare domain is attributed basically to the unique characteristics associated with mobile computing technologies, and these powerful characteristics are viable to turn m-technology into a cutting-edge tool that is able to promote healthcare systems to make it more efficient, more effective, more versatile, and delivered with high quality and reduced cost (Gurman et al., 2012; Marshall et al., 2013). Undoubtedly, $\mathrm{m}$-technologies are shifting healthcare frontiers to a new era of excellence through which patients can track health and wellness with comfort.

Apparently, the technology of mobiles has evolved rapidly over the past decade in terms of hardware and software, and it has become equipped with a wealth of appropriate features and functionalities that fit uniquely into the complex environment of healthcare delivery systems, and as a result this thriving ecosystem of m-healthcare has become a huge transformative power (Steinhubl et al., 2013). However, the introduction of mobile technology into the realm of healthcare systems has not so far enjoyed much success in terms of adoption and use by consumers (Chib et al., 2014). Therefore, mobile technology adoption in healthcare systems has yet to achieve critical mass in both developed and developing countries (Steinhubl et al., 2013). In addition to barriers like privacy and security concerns, trust concerns, regulation of the technology, consumers' readiness to adopt and use the technology and other host of problematic issues. There is an impeding characteristics associated with the nature of health domain that is clearly manifested in the fact that health is characterized by a harsh environment (Steinhubl et al., 2013), which is more than an exchange of information, and any attempt to contextualize health systems environments into a simpler form to grasp the broader picture of it is a complex process, therefore perfect transformation of this domain is an upheaval task and totally a remote possibility 
(Waters et al., 2011; Steinhubl et al., 2013). In conclusion, m-technologies and its innovations have already impacted healthcare systems since many m-healthcare applications have been appearing in numbers and have provided the following benefits: cost reduction, rich communication interactivity, increasing access, enhancing quality of services, and empowering patients with knowledge (Marshall et al., 2013). Above all, improving wellness and satisfaction of patients are highly desirable outcomes to achieve and important criteria to consider. For these reasons, the adoption of these technologies will flourish among patients.

\subsection{Healthcare in Jordan}

Jordan over the years has crossed many barriers and overcome a variety of difficulties to achieve acceptable results in securing the right healthcare services to a large majority of its citizens, specially after Jordan has achieved what is called macroeconomic stability some two decades ago. However, in comparison to many developing countries, Jordan has developed an advanced healthcare system. In fact, Jordan has become a regional leader in healthcare systems delivery. For example, medical experts from the World Bank have ranked Jordan first in health tourism in the Arab World and fifth in the World (The Jordan Times, 2012). Furthermore, 9\% of Jordan's GDP is allocated to healthcare sector, which is one of the largest worldwide (GNRD News, 2014). Still though, health problems are aggravated by an increasing rate of non-communicable diseases, high blood pressure, diabetes and obesity-related conditions among Jordanian citizens (Al-Jbour et al., 2013), and this apparently places further burdens on the country's resources. Furthermore, Jordan, like most developing countries, encounters with the harsh reality that most healthcare services are commonly concentrated in big urban cities, whereby healthcare is considerably more diversified, more sustainable, more timely, more stable, and more innovative than in rural and remote areas. To offset this imbalance, mobile-based technologies could provide the solution so that people in remote communities can gain access, with little cost, to an acceptable level of healthcare services and outcomes, and therefore achieving, to a satisfactory extent, healthcare equity across the country (Royal Scientific Society, 2013). Therefore attempting to appreciate how these technologies can be rapidly adopted and used by patients is of paramount importance to businesses and academics alike.

\subsection{Age and Technology Adoption}

It is commonly understood since the inception of computer-based technologies that the elderly have been lagging behind in the adoption and usage of these technologies (Haederle, 2011; Chen \& Chan, 2011) because the elderly for a variety of reasons are unable to access and exploit the potentials of IT capacities (Hill et al., 2008; Hsieh et al., 2008). In fact, many studies have established that the gaps of adopting and using information technologies continue to be large between old people and young people, particularly for new technologies (Dutta \& Bilbao, 2012; ICT Market, 2012; Fonchamnyo et al., 2013). Further, an empirical analysis carried out by Hung and Jen (2012) to investigate the adoption of mobile health management services in Taiwan, the study using the TAM model revealed that young adults had higher intention to adopt the technology to manage their personal health than old adults. As a result, the elderly have been deprived of IT potentials and benefits. Indeed, it is a common perception that as people get older their healthcare consumption rises disproportionately. Therefore, the elderly are in desperate need to exploit and use the new innovations in information technologies to help them manage their health conditions and illnesses.

However, in recent years the elderly have managed to handle certain Internet-assisted technologies remarkably well so that they could depend on these applications to help them remain self-reliant for longer time periods (Czaja \& Lee, 2007) such as e-healthcare applications (Klein, 2007; Payton \& Kiwanuka-Tondo, 2009; Czaja et al., 2013). In the meantime, younger people are likely to adopt a new technology long before older people (Li \& Lai, 2011) because young people of today have grown up in the presence of the recent wave of the information technology revolution, and this increases their levels of familiarity and comfortableness with technology, and therefore it is no surprise that they are becoming technologically savvy and creative and innovative users of IT applications. Consequently, it is expected that the adoption behavior towards these technologies differ in accordance with consumers' age. Correspondingly, there is a difference in the way different generations perceive m-healthcare technologies. It is therefore imperative to highlight these differences in consumers' behavior in relation to $\mathrm{m}$-healthcare environment. As a result, further investigation is highly needed to address these issues since it has not been given its due in today's literature.

\subsection{Gender and Technology Adoption}

The influence of gender on the adoption of a variety of different IT domains has been largely explored. Without a doubt, there is documented evidence in literature that men are more likely to make a decision to use a new technological innovation than women, particularly Internet technologies. For example, in the context of online environment, men are more willing to adopt online channel for purchase (Zhang et al., 2011; Ansary \& Roushdy, 
2013; Fan \& Miao, 2012; Thamizhvanan \& Xavier, 2013). Furthermore, other empirical studies have revealed that women were less concerned in using e-commerce activities than men (Hwang, 2010; Zhang et al., 2011). Cheung et al. (2011) have also observed gender differences in the context of Internet-based learning. The study of Cheung et al. has confirmed that males and females users have been found to have different perceptions in the usage of Internet medium for learning. In the context of the Facebook medium, some gender variations were observed in terms of the way this communication channel was used and handled by different genders, whereby women appear particularly more concerned with privacy issues than men (Kuo et al., 2013).

The influence of gender variations on the adoption and acceptance of m-technologies and services have been empirically acknowledged in the current literature, albeit with varying degree of influence. For instance, several empirical studies have established that there are behavioral variations between different genders in relation to the acceptance of mobile marketing (Gurau \& Ranchhod, 2009) and mobile commerce adoption (San Martín Gutiérrez et al., 2012). Further, a study based on extended TAM was conducted to investigate the influence of gender variation on the adoption and acceptance of mobile payment technology have concluded that gender differences were observed to influence the majority of proposed relationships in the TAM model (Liébana-Cabanillas et al., 2014). Another host of empirical analysis has drawn similar conclusions regarding the impact of gender on consumers' behavior of mobile payment adoption (e.g., Choi, 2010). More studies were carried out to examine the impact of gender differences on the adoption of mobile learning (Al-Fahad, 2009; Wang et al., 2009); the outcomes of these studies have confirmed the importance of gender differences on the adoption process of mobile learning technology. Further, several analysis were implemented in mobile banking domain (Laukkanen \& Pasanen, 2008; Koenig-Lewis et al., 2010; Puschel et al., 2010; Yu, 2012). These empirical studies have significantly concluded that men were more involved in the adoption process of mobile banking services than women. Additionally, an empirical analysis on the acceptance and usage of mobile data services have demonstrated that gender differences have been statistically shown to influence consumers perceptions towards the adoption of the technology (Shi et al., 2009; Yang \& Lee, 2010).

The effect of gender on the adoption, acceptance and use of e-healthcare services has not been widely addressed in literature. However, a large body of research has documented the significance of gender differences in the adoption behavior of information technologies of varying types, whereas the aspect of gender differences has not been an area of research on the adoption and acceptance of e-technologies in different medical contexts and settings (Wilkowska et al., 2010). In the meantime, a few studies have attempted to examine the effect of gender variations in the adoption of different e-healthcare applications such as: acceptance of a clinical reminder system (Zheng et al., 2006), the use of online health information (Harbour \& Chowdhury, 2007), the adoption of medical assistive devices (Wilkowska et al., 2010; Kowalewski, 2012), the use of the web for health information search (Yaşin \& Özen, 2011), the acceptance of an invasive medical stent (Ziefle \& Schaar, 2011), and the healthcare seeking behavior of tuberculosis patients (Kaur et al., 2013). Apparently, studies on m-healthcare adoption are scare and the findings already documented in literature are fragmented. One of the rare studies on the importance of gender on the acceptance of $m$-healthcare has ascertained the importance influence of gender on the context of m-healthcare adoption (Zhang et al., 2014). The study has also confirmed that men have higher levels of intention toward the adoption of m-healthcare than women.

\section{Hypothesis development}

\subsection{TAM-Related Hypotheses}

In the context of TAM model, perceived ease of use (PEOU) and perceived usefulness (PU) have been recognized as fundamentally important determinants of behavioral intention to adopt a new technological innovation (Davis, 1989). In a large spectrum of studies on various IT technologies and different settings have firmly established that these two determinants widely influence individual's perceptions to use a new technology (Ma \& Liu, 2004; Yousafzai et al., 2007; Holden \& Karsh, 2010; Turner et al., 2010; Phan \& Daim, 2011). The key factor for these determinants to prevail in the empirical analysis of adoption decisions is due to the fact that their manipulation in IS design is straightforward (Hung \& Chang, 2005). Davis (1989) defined PEOU as "the degree to which a prospective user believes that using a particular system would be effortless." and PU is defined as "the degree to which a prospective person believes that using a particular system would enhance his or her job performance." Finally, behavioral intention (BI) is a measure of motivation and willingness an individual has in order to use the technology (Davis, 1989). This particular parameter is the most important in the adoption process because the strong effect of behavioral intention would be, according to TAM theory, translated to a large extent to actual use of the technology (Davis, 1989).

A study conducted in the context of e-healthcare by Mohamed et al. (2011) has comprehensively confirmed that 
the influence of PEOU and PU on behavioral intention was significantly positive and the correlation between PEOU and PU was also positive and significant. An early study carried out to examine the acceptance of health IT technologies by clinical staff (Yu et al., 2009), they concluded that PEOU determined PU parameter. More, attempting to examine how hospital's professionals behave in the adoption process of $\mathrm{m}$-healthcare by Wu et al. (2011). The findings of their study have reported that PU can influence behavioral intention to use. In addition, the aspect of perceived ease of use can have strong influence on the perceptions of usefulness of the technology. More, an empirical analysis was set to investigate the determinants affecting consumers' intention towards m-healthcare (Lin, 2011) and Lin's analysis has revealed that PEOU and PU had potential impact on BI to use $\mathrm{m}$-healthcare technology. Further analysis has also reported that PEOU and PU were statistically significant in determining the BI to adopt m-technology (Hung \& Jen, 2012; Xue et al., 2012; Kuo et al., 2013). Also, PEOU has been identified to strongly affect PU in the context of m-healthcare innovation adoption (Hung \& Jen, 2012; Xue et al., 2012). Therefore, based on these discussions, the subsequent hypotheses are suggested.

H1: PU positively influences BI to adopt m-healthcare.

H2: PEOU positively influences BI to adopt m-healthcare.

H3: PEOU positively influences PU to adopt m-healthcare.

\subsection{External Variables: Social Influence, Trust, Security/Privacy and Cost}

It is well-established that when a certain technology is largely unknown or unfamiliar, so people will depend on others' opinions when making a decision to adopt the technology. Certainly, many have acknowledged the merit and the influence of social influence (SI) as an important social force that shape strongly adoption decisions (Venkatesh et al., 2003; Shin, 2007; Eze et al., 2011; Yanping \& Peng, 2012). Furthermore, the popular TAM3 has incorporated SI in their new expanded TAM model (Venkatesh \& Bala, 2008). The findings of the TAM3 concluded that SI affected both PU and BI to use a new IT system. In addition, a study has concluded that SI can have certain level of influence on BI to use m-technologies in healthcare (Wu et al., 2011). More, a number of studies documented that SI had influence on intentions to adopt and use m-healthcare (Xue et al., 2012; Jaradat \& Smadi, 2013; Zhang et al., 2014).

There is a consistent underlying perception that definition of trust under a unified conception is a remote possibility because the trust conceptualization varies subtly in its focus (Gefen et al., 2003; Ha \& Akamavi, 2009). As a result, an array of definitions for trust concept has emerged over the years. However, trust in relation to $\mathrm{m}$-healthcare environment can be defined as the belief that m-healthcare technology has the characteristics required to function as anticipated in a given circumstances (McKnight et al., 2011). The trust aspect has been incorporated in a wide variety of healthcare-based research studies and found to influence significantly the adoption behavior of e-healthcare (Fogel et al., 2008; Bansal et al., 2010; Mohamed et al., 2011). In the context of $\mathrm{m}$-healthcare, formation of positive trust perceptions in utilizing $\mathrm{m}$-healthcare technologies can be considered as one of the most critical parameters that requires to be accounted for in the design of the technology to improve consumers' adoption of mobile services in healthcare domains (Sorber et al., 2012; Akter et al., 2013). Because patients would never adopt systems unless they make sure that these systems are technically able to function properly and deliver accurate and reliable information to enable patients to take closely more effective role in the management of their own illnesses. Thus, one can rightly say that trust dimension can be potentially crippling to the expansion of $\mathrm{m}$-healthcare systems among patients.

In the current study, privacy in relation to m-healthcare context is referred to as the individual's right to control the acquisition, uses, or disclosures of his or her identifiable health data (Avancha et al., 2012). However, security is defined as the physical, technological, or administrative safeguards or tools used to protect identifiable health data from unwarranted access or disclosure (Avancha et al., 2012). Both privacy and security issues have surfaced in many IT domains to be a core issue that support technology adoption and diffusion (Cho et al., 2009; Zorotheos et al., 2009; Lee et al., 2011). Based on extended TAM, an empirical study conducted by Wilkowska and Ziefle (2011) established that privacy and security issues are very important determinants that influence the usage of e-healthcare technologies. Further, Liu et al. (2011) acknowledged that the electronic health records (EHRs) were extremely difficult to maintain a complete privacy of the data. The security and privacy risks associated with mobile devices are mounting enormous pressures on healthcare providers. Clearly, the open nature of the context of mobile platforms pose extremely intensified degree of uncertainty and insecurity to the safeguard of patients' private information. A survey by Beckers Hospital Review (2014) revealed that the risk of data breaching is the most worrying and impeding aspect to $\mathrm{m}$-healthcare adoption. Also, privacy and security concerns on patients' clinical data have been widely acknowledged as being significantly critical to the widespread adoption of m-technologies in various healthcare domains (Farzandipour et al., 2010; 
Sun et al., 2010; Sun et al., 2011; Fernández-Alemán et al., 2013).

Yet, healthcare professionals are recognizing the real value that $\mathrm{m}$-healthcare can add to their clinical practice. Still, however, according to a recent survey by Medical Economics (2014) that some 56\% of the respondents pointed to the fact that cost is the primary cause that they are not willing to adopt $m$-healthcare in their clinics. Many studies revealed that cost is one of the major barriers impeding the adoption of m-technologies in healthcare environments (e.g., Jen \& Hung, 2010; Banchs et al., 2014). To many old patients, the new services and technologies are of a necessity because many people lose functioning ability as they age. However, the cost burden associated with acquiring m-healthcare technology is further exacerbated by the fact that elderly people normally live in poverty and therefore the cost incurred to obtain the technology for some patients could be a big spending of money. As a result, this will lead to lower participation in the adoption of $\mathrm{m}$-healthcare technologies by the elders. Cost refers to the amount of money that consumers need to sacrifice in order to acquire a product or service (Ashton et al., 2010). Price variable has been integrated in many adoption studies to investigate its influence on the adoption process in a variety of information technologies (Kim et al., 2007; Bakar et al., 2008; Zhenyu et al., 2011; Yu, 2012). However, in the context of TAM model, very little research has been carried out to incorporate SI, trust, security/privacy, and cost parameters as external variables in the TAM, particularly for the context of $\mathrm{m}$-healthcare. Thus, with reference to the above findings and conclusions, the subsequent hypotheses are recommended for the current investigation.

H4: SI positively influences BI to adopt m-healthcare.

H5: SI positively influences PU to adopt m-healthcare.

H6: Trust positively influences the PU to adopt m-healthcare.

H7: Trust positively influences the PEOU to adopt m-healthcare.

H8: Security/privacy negatively influences the PU to adopt m-healthcare.

H9: Security/privacy negatively influences the PEOU to adopt m-healthcare.

H10: Cost negatively influences the PU to adopt $\mathrm{m}$-healthcare.

H11: Cost negatively influences the PEOU to adopt m-healthcare.

\subsection{Moderating Effect of Age}

It is apparent from literature that age is a vital parameter to consider in IT adoption studies. In fact, quite extensively researchers worldwide have carried out a plethora of studies to understand how age impacts the adoption and acceptance processes of various IT systems and applications (Morris \& Venkatesh, 2000; Venkatesh \& Davis, 2000; Cutler et al., 2003; Hung et al., 2003; Venkatesh et al., 2003; Chang et al., 2005; Porter \& Donthu, 2006; Liao et al., 2007; Zhou et al., 2007; Passyn et al., 2011; Fan \& Miao, 2012; Ansary \& Roushdy, 2013; Chong, 2013; Fonchamnyo, 2013). The results of these studies have clearly and significantly labeled that age differences play a considerable role in the decision-making process of information technologies adoption. Further, an important study conducted in the context of e-healthcare systems (Whittaker et al., 2011) established that older nurses have exhibited more reluctance to use m-technologies in their work environment than young nurses.

The moderating influence of age on primary TAM-related relationships has not been largely tested (Chung et al., 2010). This study, using the TAM theory as a theoretical framework, is set to underline the moderating influence of age-related variations in patients' perceptions in the adoption of an emerging innovation of $m$-healthcare technology. The presence of the differences in individual perceptions and behavior between young and old people toward PEOU determinant is attributed primarily to the fact that old people generally encounter some special physical and mental health challenges that impede their efficacy to learn quickly, such as age-related decline in cognitive ability, difficulty in adopting a new information processing systems that are unknown and unfamiliar to them, and inadequate experience and lack of knowledge of IT applications (Van de Watering, 2007; Chung et al., 2010; Liao \& Fu, 2014). This generates a feeling of perceived difficulty, which potentially restricts the ability of older people to display high level of ease of use perceptions toward the adoption and acceptance of a technology. Unlike young people who are extremely agile to accomplish all kinds of IT-based tasks willingly regardless to their degree of difficulties. However, Yousafzai and Yani-de-Soriano (2012) have verified that age moderated the relationship between PEOU and BI in the context of Internet banking, the moderating effect was stronger for older generations than young generations. Furthermore, in e-banking domain, Li and Lai (2011) concluded that older e-banking users were more influenced by PU than younger users (Venkatesh et al., 2003). Further, based on findings of many empirical analyses, it has been established that age increases the positive 
influence of SI on BI because increasing age results in people placing greater emphasis on affiliation (Morris \& Venkatesh, 2000; Burton-Jones \& Hubona, 2006). Finally, a critical examination of the literature indicates that there has been little empirical research that investigates the moderating effects of age differences among primary TAM-related relationships in both healthcare and non-healthcare domains. However, according to the discussions presented above, the current empirical study predicts that age differences moderate the primary TAM-related relationships. Therefore, the following hypotheses are suggested.

H20: Age moderates PEOU-BI relationship to adopt m-healthcare in a way that it is stronger for younger people than older people.

H21: Age moderates PU-BI relationship to adopt m-healthcare in a way that it is stronger for older people than younger people.

H22: Age moderates PEOU-PU relationship to adopt m-healthcare in a way that it is stronger for younger people than older people.

H12: Age moderates SI-BI relationship to adopt $m$-healthcare in a way that it is stronger for older people than younger people.

H13: Age moderates SI-PU relationship to adopt m-healthcare in a way that it is stronger for older people than younger people.

A host of empirical studies conducted on the adoption of different information system domains have established that older generations tended to be excessively susceptible to uncertainty and fraudulent activities more than younger generations, particularly in virtual environments (e.g., Castle, 2012). These undesirable feelings would definitely communicate lack of trust and untrustworthiness to prospective users of the technology and therefore generate negative perceptions and correspondingly causing increased backlash toward acceptance of the technology. Undeniably, these unfavorable aspects and consequences of technology adoption which have been generated as a result of lack of trust among potential consumers have dramatically intensified the importance of trust dimension in Internet and mobile-based communication channels.

An adoption analysis conducted in the context of mobile payment concluded that age introduced significant differences in the relationships between trust and PEOU (Liébana-Cabanillas et al., 2014). Further, Zulman et al. (2011) documented that people above 65 years old are found to be considerably the least likely to trust the Internet channel for healthcare information. The current literature provides evidence that older people are more wary of trusting the new technologies (Peter \& Valkenburg, 2011), particularly in a virtual environment (Yao et al., 2007). Therefore, older people will be more reluctant to release their sensitive information through mobile channels. Unlike, younger people who tend to be more likely to expose their personnel data and less worried about their privacy (Parker \& Parrott, 1995; Taddicken, 2014). Further, many empirical studies have revealed that security and privacy concerns increase with age (Zukowski \& Brown, 2007; Hoofnagle et al., 2010; Walrave et al., 2012). More, the influence of cost on the adoption of many e-technology studies has to a large degree been overlooked. However, many studies have argued that cost is one of the most critical factors in explaining older consumers' behavior toward the acceptance of a new technology (Mallenius et al., 2007; Steele et al., 2009). In the meantime, Chen and Chan (2011) established that cost aspect was one of the critical factors that determines older people's perceptions toward adoption of the technology. Finally, the current literature has limited empirical analysis of how age differences moderate the relationships between the conceptualized external factors of trust, security/privacy and cost factors with the two most important determinants of the TAM model: PEOU and PU. Based upon the findings of the studies reported above, the current empirical investigation deems that the following hypotheses to be proposed.

H14: Age moderates trust-PU relationship to adopt m-healthcare in a way that it is stronger for older people than young people.

H15: Age moderates trust-PEOU relationship to adopt $\mathrm{m}$-healthcare in a way that it is stronger for younger people than older people.

H16: Age moderates security/privacy-PU relationship to adopt m-healthcare in a way that it is stronger for older people than younger people.

H17: Age moderates security/privacy-PEOU relationship to adopt m-healthcare in a way that it is stronger for older people than younger people.

H18: Age moderates cost-PU relationship to adopt m-healthcare in a way that it is stronger for older people than younger people. 
H19: Age moderates cost-PEOU relationship to adopt m-healthcare in a way that it is stronger for older people than younger people.

\subsection{Moderating Effect of Gender}

Gender is defined as a set of characteristics differentiating between men and women and masculine from feminine traits. According to Gefen and Straub (1997), gender refers to as a fundamental sociocultural aspect, which can impact individuals' perceptions and behaviors considerably. Therefore, it has become imperative to detect the gender's moderating effect on technology acceptance process. Hernandez et al. (2011) attributed the presence of gender differences in IS/IT technology adoption behavior to three gender characteristics: (1) Men are pragmatic by nature, (2) women exhibit higher levels of technophobia and therefore experience greater anxiety when using new technologies or facing new challenges, and (3) women have higher tendency to be affected by their immediate environment and surroundings. It is prevalent in empirical literature that men and women have different perceptions in relation to PEOU and PU in the process of making decisions related to the adoption of technologies. Clearly, many research studies confirmed that men place heavy emphasis on achievement-related tasks and accomplishments such as PU, whereas women tend to be highly influenced by PEOU (Zhang, 2009; Venkatesh \& Morris, 2003). Further, a highly popular study conducted by Venkatesh et al. (2003) confirmed the moderating influence of gender on the user's acceptance of IT. Their study found that the influence of PU on BI is moderated by gender differences and the influence is greater for men as compared to women. Many empirical analysis conducted in different IT domains have reported that men are highly influenced by PU (Ong \& Lai, 2006; Shin, 2009; Choi, 2010; Pan \& Jordan-Marsh, 2010; Van Slyke et al., 2010; Goh, 2011). However, the influence of PEOU on BI was found to be stronger among women. In fact, many empirical results have revealed that women unlike men are highly motivated by PEOU (Ong \& Lai, 2006; Pan \& Jordan-Marsh, 2010). In addition, the work of Venkatesh et al. (2003) concluded that women's PEOU influenced PU more strongly than men. Further, more empirical investigation reported outcomes similar to Venkatesh et al. (Amin, 2007; Riquelme \& Rios, 2010). Moreover, SI has been reported to influence PU and BI more strongly for women than men (Venkatesh et al., 2003). Further, investigating the role of SI from a gender perspective, the literature on gender differences suggests that women are more inclined to conform to majority opinions compared with men (Lu et al., 2009; Riquelme \& Rios, 2010, Hamza \& Shah, 2014). Based on the above arguments, the following hypotheses are proposed.

H32: PU influences BI to adopt m-healthcare more strongly for men than women.

H33: PEOU influences BI to adopt $m$-healthcare more strongly for women than men.

H31: PEOU influences PU to adopt m-healthcare more strongly for women than men.

H23: SI influences BI to adopt m-healthcare more strongly for women than men.

H24: SI influences PU to adopt m-healthcare more strongly for women than men.

The current literature is rich with robust evidence demonstrating that lack of consumer trust is a critical obstacle in the progression and development of any business endeavor. However, in online and mobile contexts, the criticality of this issue is further exacerbated. However, there is a limited literature addressing how gender differences influence people's trust perceptions toward adoption of a new technology, particularly in relation to $\mathrm{m}$-healthcare. Yet, extensive empirical analysis established that women have the tendency to demonstrate lower degrees of trust perceptions toward adoption of online channel for purchase when compared with men (Cho \& Jialin, 2008; Dennis et al., 2010; Santos \& Fernandes, 2011). In fact, it is apparent from literature that women generally perceive higher level of risk and uncertainty than men when making an adoption decision, and this leads women to report higher degree of security/privacy concerns than men (Jensen et al., 2005; Fogel \& Nehmad, 2009; Michota, 2013). Therefore, women will be more reluctance to release their sensitive personal health data and this may well hamper the pace of adoption of technology-assisted healthcare systems such as e-healthcare and m-healthcare technologies (Wilkowska \& Ziefle, 2011). Furthermore, different genders may exhibit different price perceptions. Inherently, women tend to be more involved in price issues than men (Venkatesh et al., 2012). However, investigating empirically how the gender differences affecting trust, security/privacy and cost perceptions on PEOU and PU in healthcare fields are not abundantly researched. To our knowledge, with respect to the context of $\mathrm{m}$-healthcare, this study is the first to extend the original TAM theory with such variables. Therefore, based on the above results and arguments, the following hypotheses are deemed suitable for the current analysis.

H25: Trust influences PU to adopt m-healthcare more strongly for men than women.

H26: Trust influences PEOU to adopt m-healthcare more strongly for women than men. 
H27: Security/privacy influences PU to adopt $m$-healthcare more strongly for women than men.

H28: Security/privacy influences PEOU to adopt m-healthcare more strongly for women than men.

H29: Cost influences PU to adopt m-healthcare more strongly for women than women.

H30: Cost influences PEOU to adopt m-healthcare more strongly for women than men.

\section{Research Model}

The present study extends the original TAM model with the addition of factors to account for the social influence, trust aspect, security/privacy concerns and cost issue. This study also intends to investigate the age- and gender-related differences. The research model is shown in Figure 1.

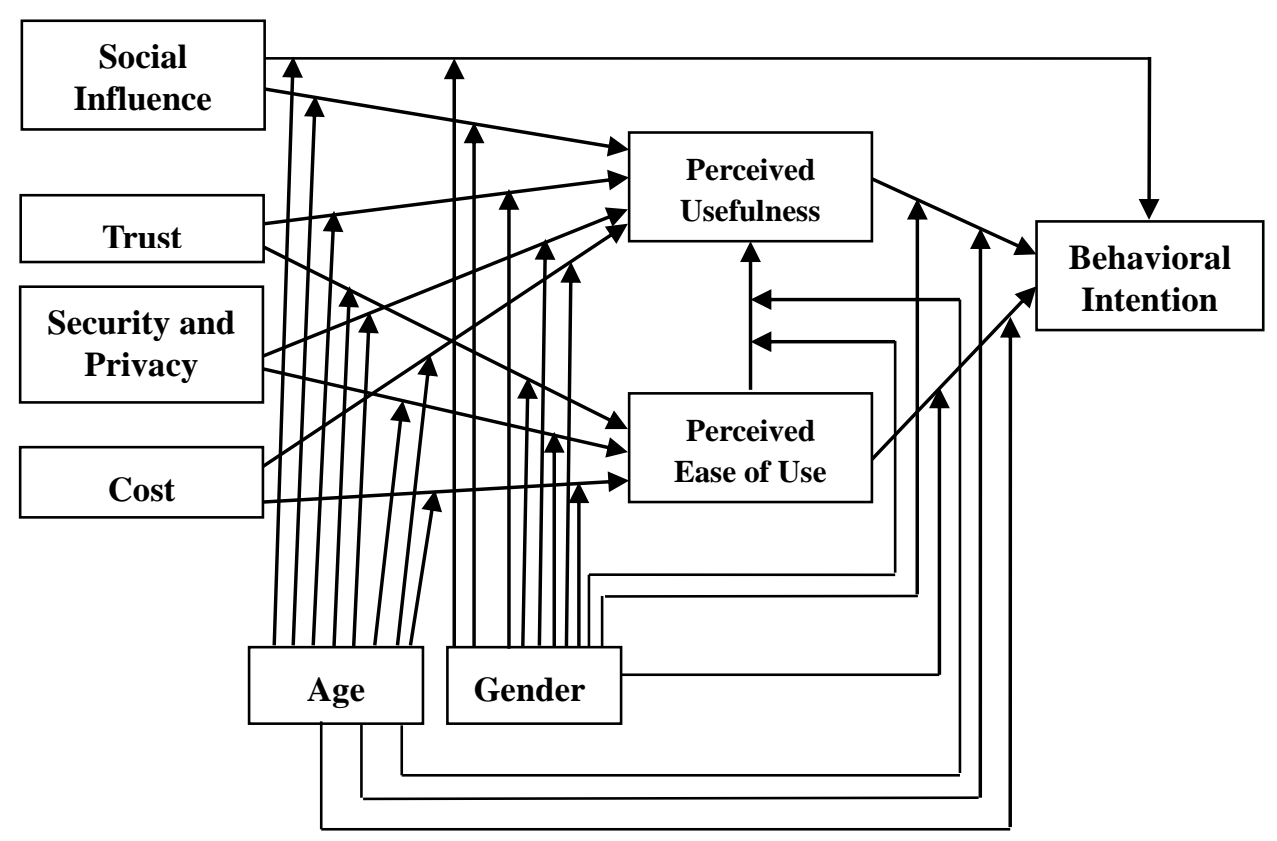

Figure 1. Research model of the study

\section{Research Method}

The current preliminary study intends to examine the parameters responsible for improving the chances of patients participating in the adoption and acceptance of $\mathrm{m}$-healthcare. In reality, $\mathrm{m}$-healthcare technologies are novel innovations to most developing countries' cultures and economies and their adoptions have been little investigated in these environments, particularly with respect to the Jordanian environment. M-healthcare is fundamentally one of the most important technological innovations that have recently emerged which hold the promise of substantially renovating healthcare domains. However, the adoption of these types of technologies has not been conclusively established in relation to patients' perceptions and perspectives and therefore their behaviors toward these technologies are unknown to the academic community. In fact, we should expect patients to be significantly proactive in pursuing productive ways to appropriately ease off the pressure of their illnesses on their daily life. As a result, we anticipate that patients to be willing by default to adopt mobile-based technologies to help them manage and control positively and independently their illnesses. In the meantime, the adoption of these technologies by patients in developing country contexts can not be assumed to follow the same mainstream of previous technologies. Indeed, $\mathrm{m}$-healthcare domain is still a gray area in terms of adoption and acceptance among patients in developing country environments. Therefore, this study can, to some extent, be considered explorative in nature. Consequently, the popular PLS based on Structural Equation Modeling (SEM) statistical technique can best suit the contexts of the current study.

\subsection{Instrument}

In order to validate and achieve the purposes of this empirical research, we developed a survey questionnaire having 25 questions (measurement items) organized around seven constructs (SI, Trust, Security/privacy, Cost, 
PEOU, PU, BI). To ensure the validity of the questionnaire, questions utilized in the current study were adapted from previously validated works in the field (Davis, 1989; Davis \& Venkatesh, 1995; Lin \& Wu, 2002; Gefen et al., 2003; Luarn \& Lin, 2005; Venkatesh et al., 2003; Yang \& Peterson, 2001). The wording of the questions was tailored to suit the context of $\mathrm{m}$-healthcare environment. Since the original questions were initially developed in English language, therefore a translation of these items from English into Arabic were done by a panel of experts. These experts are native Arabic speakers with an excellent command of English language and knowledgeable in this field of this study. This survey has employed the popular 5-point Likert scale $(1=$ strongly disagree, $2=$ disagree, $3=$ neutral, $4=$ agree, $5=$ strongly agree) $($ see Appendix A).

\subsection{Sample}

The current work was implemented at a number of hospitals in Jordan. The relevant data was gathered from participants (outpatients) by paper-based survey using the probability sampling technique. The stratified random sampling method was particularly employed to guarantee sufficient representation of subgroups within the population. The researchers have selected this type of traditional data collection method, as it is effective even though it is costly and time-consuming. Indeed, collecting data by means of online mediums such as e-mails or social networks may not be a useful approach because it is not an easy task to reach out patients online in this part of the world. In addition, according to Nulty (2008) that web-based surveys yield usually slow response rates. This study has selected a sample of 450 participants and the sample size is inline with requirements proposed by Sekaran (2006), 376 questionnaires were returned, corresponding to a return rate of almost $84 \%$. Ten of these questionnaires were dropped due to missing respondent data and errors, leaving 366 valid questionnaires for statistical analysis. Table 1 presents the profile study participants. The statistical findings of the current research have shown that more than half of the respondents were female (56.8\%). Further, Some 60\% of the respondents lie in the age range between 20 and than 29 . Only $4.6 \%$ of the respondents over the age of 50 . Regarding the level of education, it is apparent from Table 1 that large percentages of the respondents hold a bachelor degree (59\%) and almost half of respondents spend between 250-500 JDs monthly.

Table 1. Profile study participants

\begin{tabular}{lccc}
\hline Variable & & Frequency & Percentage \\
\hline \multirow{2}{*}{ Gender } & Female & 208 & .80 \\
& Male & 158 & 43.20 \\
& 20 or Less & 28 & 07.70 \\
Age (years) & Between 20 and 29 & 220 & 60.10 \\
& Between 30 and 39 & 83 & 22.70 \\
& Between 40 and 49 & 18 & 04.90 \\
& More than 50 & 17 & 04.60 \\
Monthly expense & 250 or Less & 80 & 21.90 \\
& 250 Less than 500 & 200 & 54.60 \\
& 500 Less than 1000 & 59 & 16.10 \\
& More than 1000 & 2 & 0.50 \\
& Secondary school or less & 84 & 23.00 \\
Education level & Diploma certificate & 43 & 11.70 \\
& Bachelor degree & 217 & 59.30 \\
& Master degree & 18 & 04.90 \\
& PhD degree & 4 & 01.10 \\
\hline
\end{tabular}

\subsection{Data Analysis}

As already mentioned that, in order to quantitatively analyze the correlation among the relationships assumed in the current research, the powerful statistical tool of PLS (WarpPLS 4.0) is used. WarpPLS 4.0 is based on the variance-based PLS-SEM statistical technique and it is best suited for complex causal model with numerous parameters and relationships (Pavlou \& Fygenson, 2006; Ahuja et al., 2007; Au et al., 2008). Further, PLS can be more effective than other software in this field of study to analyze and study the moderating effects of moderator variables (Pavlou \& El Sawy, 2006; Limayem et al., 2007), as similar to the current study. WarpPLS 4.0 offers quality indices that can be seen as an indication of the quality of the modeling technique, including the ten goodness-of-fit indices (see Table 3 below), p-values and multicollinearity calculations (Kock, 2013). In addition, a recent review by Hair et al. (2012) on the application of SEM-based PLS technique in the academic fields, they concluded that this statistical tool has, in recent years, gained growing exposure, publicity, and acceptance 
among academics and practitioners alike. In the meantime, Richter et al. (2015) have discussed why PLS-SEM method is becoming critically versatile, as it has been extensively used in empirical analysis in a diversity of applications, and the use of PLS-SEM method in empirical analysis is also appearing in numbers in high ranking management journals. Adding to that, many adoption studies have used different variants of PLS in their analysis in relation to the Jordanian environment; these studies have concluded that the PLS-SEM method is satisfactorily employed in these empirical-based adoption studies. For example, the adoption of Internet channel for buying (Faqih, 2011; Faqih, 2013), mobile payment adoption (Jaradat \& Faqih, 2014), mobile commerce adoption (Faqih \& Jaradat, 2014), and mobile learning adoption (Jaradat, 2014).

\subsection{Reliability and Validity}

The WarpPLS 4.0 is utilized to assess the measurement model of the data by examining the reliability and validity of measurement instruments, these assessments had been achieved through evaluating the convergent validity and reliability of all measurement items and followed by the measurement of discriminant validity. Statistically, it has been confirmed that Cronbach's alpha, Composite reliability (CR), Average variance extracted (AVE), and factor loading can be utilized to investigate with adequacy both convergent validity and reliability of the measurement items. Cronbach's alpha is a coefficient of reliability utilized to examine the internal consistency reliability (homogeneity) of the scale measurement items, or how well the items measure the same construct. The calculated values of Cronbach's alpha (Table 2) range from 0.719 (Cost) to 0.837 (BI), the level of these values clearly show that all the constructs exhibit adequate reliability as their values are exceeding the recommended threshold of 0.6 (Hair et al., 2003). The composite reliability (CR) is also an important statistical measurements utilized to evaluate the internal consistency of items measuring the constructs. The composite reliability which ranges from 0.842 to 0.902 (Table 2) are indicative of the fact that these values satisfy the statistical requirements set by Chin et al. (2003), they indicated that composite reliability is suggested to numerically exceed 0.70 . As shown in Table 2, the AVE values for all variables included in this study are greater than the value of 0.50 suggested by Fornell and Larcker (1981). Furthermore, the AVE value for each variable was evaluated in this study to test discriminant validity of the constructs. To confirm whether certain constructs have adequate discriminant validity, Fornell \& Larcker's (1981) approach was applied. As shown in Table 2, in accordance with requirements set by Fornell and Larcker (1981), the square root of AVE for each construct is higher than the correlations between the constructs and all other constructs, demonstrating that these constructs exhibit adequate discriminant validity. Mean and standard deviations for variables and factor loading for measurement items are shown in Appendix A. All factor loadings range from 0.66 to 0.87 , and these values are exceeding the minimum value of 0.6 recommended by Goffee (1996). However, one of the items measuring trust construct was deleted due to factor loading below 0.6.

In fact, multicollinearity problems are potentially likely to occur when factor loadings measuring the same construct are exceeding 0.7. The current study, with the help of WarpPLS 4.0, has evaluated the variance inflation factors (VIFs), Average block VIF (AVIF) and Average full collinearity VIF (AFVIF) for all items measuring the variables of the current model. Apparently, since all values calculated for VIFs are less than 5 (Table 2), the model is therefore not suffering from a multicollinearity problem (Hair et al., 2009). Additionally, to confirm that the current model exhibits no risk of multicollinearity, the computed values of AVIF $(=1.493)$ and AFVIF (= 1.534) (Table 3) are below the threshold value of 3.30 proposed by Cenfetelli and Bassellier (2009). In conclusion, the findings of the current analysis provide evidence that this model possesses sufficient reliability and construct validity.

Table 2 . Scale reliability and validity

\begin{tabular}{lccccccccccccc}
\hline Variables & $\begin{array}{l}\text { Cronbach's } \\
\text { alpha }\end{array}$ & $\begin{array}{l}\text { Composite } \\
\text { reliability }\end{array}$ & R-square VIFs & AVE & 1 & 2 & 3 & 4 & 5 & 6 & 7 \\
\hline 1 & Social Influence & 0.790 & 0.864 & 0.00 & 1.546 & 0.614 & 0.784 & & & & & \\
2 & Trust & 0.748 & 0.842 & 0.00 & 1.499 & 0.573 & 0.392 & 0.757 & & & & \\
3 & Security/ Privacy & 0.736 & 0.850 & 0.00 & 1.656 & 0.654 & 0.391 & 0.480 & 0.809 & & & \\
4 & Cost & 0.719 & 0.842 & 0.00 & 1.160 & 0.641 & 0.022 & 0.103 & 0.037 & 0.800 & & \\
5 & Perceived Usefulness & 0.754 & 0.860 & 0.38 & 1.754 & 0.671 & 0.323 & 0.297 & 0.323 & 0.017 & 0.819 & \\
6 & Perceived Ease of Use & 0.739 & 0.852 & 0.17 & 1.674 & 0.658 & 0.292 & 0.269 & 0.338 & 0.041 & 0.478 & 0.811 \\
7 & Behavioral Intention & 0.837 & 0.902 & 0.48 & 1.925 & 0.754 & 0.385 & 0.283 & 0.315 & 0.097 & 0.548 & 0.549 & 0.868 \\
\hline
\end{tabular}

(Square roots of the AVE are the bolded diagonal values) 


\subsection{Results}

The current model incorporates seven variables: Social influence, trust, security/privacy, cost, perceived usefulness, perceived ease of use, and behavioral intention. This study has suggested 11 hypotheses linking the model's variables as deemed important for achieving the intentions of this investigation. Besides, the two basic demographics of age and gender have been utilized as moderators in the current model, attempting to gauge the moderating influence of age and gender differences on the 11 hypotheses suggested in the current model. Therefore, the total number of hypotheses proposed in this model has become 33. The WarpPLS 4.0 was employed to examine the structural model. The goodness-of-fit $(\mathrm{GoF})$ indices, computed by WarpPLS 4.0, are shown in Table 3. These indices statistically describe how well the measurement model fits its data. Apparently, the statistical findings obtained here strongly indicate that there is an acceptable fit between the data and the measurement model (Kock, 2013). The testing of the structural model has been performed through the use of WarpPLS 4.0. Figure 2 summarizes the outcomes of the hypothesis testing. Table 4 also illustrates the hypothesis testing results of the structural model in more details. The results obtained provided statistical evidence to support 17 out of the 33 hypotheses suggested in this study. In addition, the model explained high-level variance among the dependent variables such as PU $(\mathrm{R} 2=0.41)$ and $\mathrm{BI}(\mathrm{R} 2=0.48)$.

Table 3. Model evaluation overall fit measurement.

\begin{tabular}{lll}
\hline Measure & Value & $\mathrm{p}$-values \\
\hline Average path coefficient (APC) $(<0.05)$ & 0.099 & $\mathrm{p}=0.007$ \\
Average R-squared (ARS) (<0.05) & 0.341 & $\mathrm{p}<0.001$ \\
Average adjusted R-squared (AARS) & 0.321 & $\mathrm{p}<0.001$ \\
Average block VIF (AVIF) & 1.493 & Good if $<=5$, ideally $<=3.3$ \\
Average full collinearity VIF (AFVIF) & 1.534 & Acceptable if $<=5$, ideally $<=3.3$ \\
Tenenhaus GoF (GoF) & 0.479 & Small $>=0.1$, medium $>=0.25$, large $>=0.36$ \\
Sympson's paradox ratio (SPR) & 0.788 & Acceptable if $>=0.7$, ideally $=1$ \\
R-squared contribution ratio (RSCR) & 0.981 & Acceptable if $>=0.9$, ideally $=1$ \\
Statistical suppression ratio (SSR) & 0.970 & Acceptable if $>=0.7$ \\
Nonlinear bivariate causality direction ratio (NLBCDR) & 0.864 & Acceptable if $>=0.7$ \\
\hline
\end{tabular}

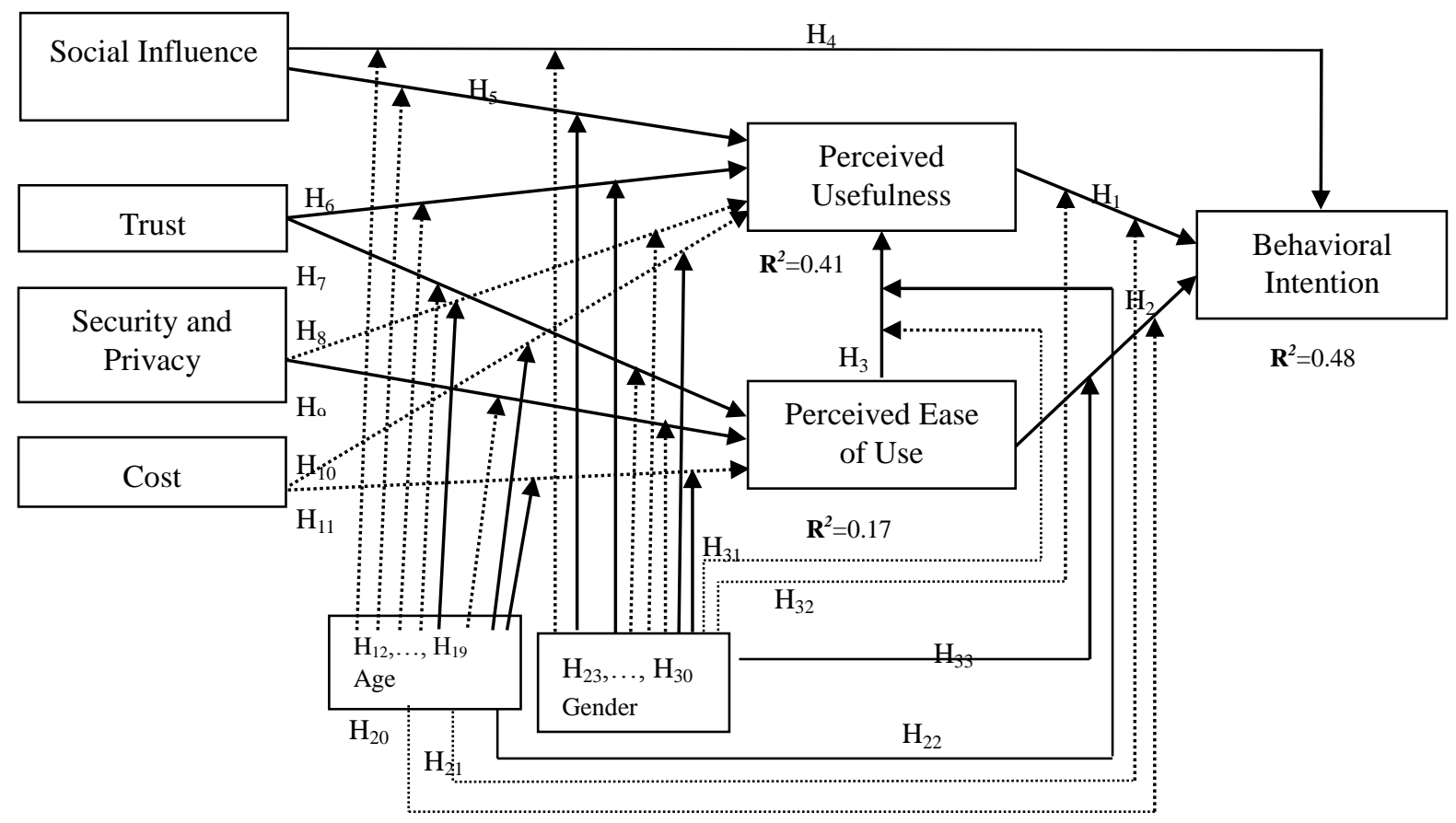

Figure 2. Results of testing hypotheses

Note. Sold line indicates that the hypothesis is supported, where dotted line indicates that the hypothesis is not supported. 
Table 4. Result of model hypotheses test

\begin{tabular}{|c|c|c|c|c|c|}
\hline No. & $\begin{array}{l}\text { Dependent } \\
\text { Variables }\end{array}$ & $\begin{array}{l}\text { Independent } \\
\text { Variables }\end{array}$ & Moderators & Path Coefficient & Supported \\
\hline $\mathrm{H} 1$ & $\mathrm{PU}$ & $\mathrm{BI}$ & & $0.313^{* * *}$ & Yes \\
\hline $\mathrm{H} 2$ & PEOU & $\mathrm{BI}$ & & $0.328 * * *$ & Yes \\
\hline $\mathrm{H} 3$ & $\mathrm{PU}$ & PEOU & & $0.409 * * *$ & Yes \\
\hline $\mathrm{H} 4$ & SI & BI & & $0.167 * * *$ & Yes \\
\hline H5 & SI & $\mathrm{PU}$ & & $0.110^{* *}$ & Yes \\
\hline H6 & Trust & $\mathrm{PU}$ & & $0.131 * *$ & Yes \\
\hline $\mathrm{H} 7$ & Trust & PEOU & & $0.114 * *$ & Yes \\
\hline $\mathrm{H} 8$ & Security/privacy & $\mathrm{PU}$ & & 0.072 & No \\
\hline H9 & Security/privacy & PEOU & & $0.272 * * *$ & Yes \\
\hline $\mathrm{H} 10$ & Cost & PU & & 0.011 & No \\
\hline H11 & Cost & PEOU & & 0.013 & No \\
\hline $\mathrm{H} 12$ & SI & $\mathrm{BI}$ & age & 0.002 & No \\
\hline H13 & SI & PU & age & 0.023 & No \\
\hline H14 & Trust & $\mathrm{PU}$ & age & 0.029 & No \\
\hline H15 & Trust & PEOU & age & 0.075 & No \\
\hline H16 & Security/privacy & PU & age & $0.104 *$ & Yes \\
\hline H17 & Security/privacy & PEOU & age & -0.037 & No \\
\hline H18 & Cost & PU & age & $-0.129 * *$ & Yes \\
\hline H19 & Cost & PEOU & age & $-0.088^{*}$ & Yes \\
\hline $\mathrm{H} 20$ & PEOU & BI & age & -0.070 & No \\
\hline $\mathrm{H} 21$ & $\mathrm{PU}$ & $\mathrm{BI}$ & age & 0.019 & No \\
\hline $\mathrm{H} 22$ & PEOU & PU & age & $0.127 * *$ & Yes \\
\hline $\mathrm{H} 23$ & SI & $\mathrm{BI}$ & gender & -0.014 & No \\
\hline $\mathrm{H} 24$ & SI & PU & gender & $0.087^{*}$ & Yes \\
\hline $\mathrm{H} 25$ & Trust & $\mathrm{PU}$ & gender & $-0.076^{*}$ & Yes \\
\hline $\mathrm{H} 26$ & Trust & PEOU & gender & 0.056 & No \\
\hline $\mathrm{H} 27$ & Security/privacy & PU & gender & -0.005 & No \\
\hline $\mathrm{H} 28$ & Security/privacy & PEOU & gender & 0.049 & No \\
\hline $\mathrm{H} 29$ & Cost & PU & gender & $0.10^{* *}$ & Yes \\
\hline H30 & Cost & PEOU & gender & $0.107 * *$ & Yes \\
\hline $\mathrm{H} 31$ & PEOU & $\mathrm{PU}$ & gender & 0.049 & No \\
\hline H32 & $\mathrm{PU}$ & $\mathrm{BI}$ & gender & 0.011 & No \\
\hline H33 & PEOU & $\mathrm{BI}$ & gender & $0.090 *$ & Yes \\
\hline
\end{tabular}

Significance at $\mathrm{p}<* * *: 0.001, * *: 0.01, *: 0.05$.

\section{Discussion of Findings}

The current study proposes a model based on an extended TAM to investigate the adoption of m-healthcare adoption in Jordan. The TAM model has been augmented with four external variables; these are social influence, trust, security/privacy and cost. Besides, studying the applicability and adaptability of TAM theory in mobile healthcare domain and developing countries' environment. The current study also aims to examine the influence of demographic variables of age and gender differences on patients' perceptions and behaviors towards the adoption of mobile-healthcare domain. The findings highlighted in this study offer a considerable opportunity for the Arab world in general and Jordan in particular to make use of these findings in order to better develop and implement strategies for the benefits of enhancing the adoption and diffusion of $\mathrm{m}$-technologies in healthcare domains among patients. Nevertheless, there are limited research in the current literature examining the adoption of mobile healthcare in relation to patients' perceptions and perspectives for comparison with the results obtained by this study. In the light of this scarcity of literature in age and gender-related differences, it is useful to make comparisons with findings drawn from different IS/IT scholarly domains whereby the influence of age and gender differences were heavily investigated.

The current findings have established that PEOU and PU are key predictors of patients' intention to adopt mobile healthcare technology with almost similar explanatory power $(H 2: \beta=0.328, p<0.001 ; H 1: \beta=0.313, p<0.001)$. 
Similar findings were reported by information technology adoption studies implemented in the context of different healthcare domains (Lin, 2011; Mohamed, 2011; Hung \& Jen, 2012; Xue et al., 2012; Jaradat \& Smadi, 2013; Kuo et al., 2013). In fact, the strength of PU and BI relationship is obviously comparable to prior studies in the field, however the strength of the relationship between PEOU and BI is much stronger than what concluded by previous studies. This result indicates that the respondents of this study lack the technical knowledge necessary to successfully use m-technology to achieve better healthcare delivery for themselves. Correspondingly, it appears that most respondents of this study are not comfortable with m-technology usage for health applications. For that reason, they might perceive the aspect of ease of use as a highly significant and a critical issue. Overall, with respect to the findings of PEOU and PU influence on BI, it implies that if patients find the technology simple, easy to use and useful they will be keen to participate in its adoption. Also, this study empirically shows that PEOU is significantly correlated with PU (H3: $\beta=0.409, p<0.001)$. This result conforms with prior findings (Mohamed, 2011; Wu et al., 2011; Hung and Jen, 2012; Xue et al., 2012). The current result implies that if the individuals feel that the m-healthcare is easy to use and effortless to manage they will tend to perceive it as useful. The conclusion of the current findings is that PEOU influences the intention to use $\mathrm{m}$-healthcare directly and indirectly though PU construct. The results obtained by the current study concerning the primary TAM-related relationships conform well with many previous conclusions reported by other research studies in different IT domains. This study statistically also reveals that SI is positively correlated with BI to adopt $\mathrm{m}$-healthcare (H4: $\beta=0.167, \mathrm{p}<0.001)$. Similar results were concluded by studies carried out in different healthcare domains (Xue et al., 2012; Jaradat \& Smadi, 2013; Sun et al., 2013; Zhang et al., 2014). Other studies conducted in Jordan on the adoption of mobile-commerce (Faqih \& Jaradat, 2014) and m-payment (Jaradat \& Faqih, 2014) using students as respondents have reported less predictive power regarding the influence of SI on BI. The interpretation of the variation in the result can be presumably attributed to the reality that this current study used a sample of higher average age of respondents than other studies. Furthermore, this study confirms that SI positively influences PU (H5: $\beta=0.110, p<0.01)$, which also positively and indirectly influences BI to adopt and use the technology. These results corroborate with similar findings reported by previous studies (Venkatesh \& Davis, 2000; Venkatesh \& Bala, 2008).

Furthermore, trust is positively associated with both PEOU and PU (H7: $\beta=0.114, p<0.01 ;$ H6: $\beta=0.131, p<$ 0.01 ). As a result, trust has an indirect positive influence on patients' intention to adopt $m$-healthcare via PEOU and PU. Similarly, in the context of e-healthcare, a study concluded that trust exerted strong positive direct influence on professionals' PEOU and PU (José \& María, 2011). The findings obtained here are similar to those achieved by studies in non-healthcare domains (Tang \& Chi, 2005; Chau et al., 2007; Reid \& Levy, 2008; Sharif, et al., 2014). However, Jaradat and Smadi, (2013) concluded that trust dimension had no direct effect on the users' behavioral intention to adopt m-healthcare.

The current result also shows that security/privacy has a significant and direct positive influence on PEOU (H9: $\beta=0.272, \mathrm{p}<0.001$ ), which in turn influences BI to adopt $\mathrm{m}$-healthcare. The strong correlation between security/privacy and PEOU is an indication of the fact that the higher the security and privacy perceptions of the technology the higher patients' perceptions of ease of use of the technology, and this will lead to a greater level of BI and finally to actual use of the systems. These findings are in agreement with findings obtained by earlier studies conducted on non-healthcare domains (Lallmahamood, 2007; Nasri et al., 2013). In the meantime, the current study also reports that security/privacy has no effect on PU (H8), and therefore no indirect effect on BI. This result clearly indicates higher patients' perceptions of security/privacy will not lead patients to perceive the technology as useful to their jobs and patients become less to adopt the technology. However, these results are not in line with some previous findings carried out in healthcare and non-healthcare fields (Lallmahamood, 2007; Wilkowska \& Ziefle, 2011; Nasri et al., 2013).

Besides, this study shows that cost shows no influence on both PEOU and PU (H11: $\beta=0.013, p<0.05 ;$ H10: $\beta$ $=0.011, \mathrm{p}<0.05)$. Contrary to what has been hypothesized in the current model, the current results have revealed that cost has insignificant role to play in mobile healthcare adoption. The current results are not in harmony with results provided by Garg and Garg (2013) on the acceptance of 3G. The current results may be attributed to either respondents are unaware of the cost of $\mathrm{m}$-healthcare innovations since they have not used the technology, or Jordanians may be driven by the fact that m-technology is handy and cheap in Jordan (Arab Advisers Group, 2013). However, these results contradict previous findings concluded by adoption studies implemented in Internet and mobile-based environments (Chong et al., 2012; Yu, 2012).

The current result demonstrates that age moderates the link between PEOU and PU in a way that it is stronger for older people (H22: $\beta=0.127, \mathrm{p}<0.01)$, however, this study has conceptualized that the relationship is stronger for younger people. This means that older people who find the technology easy to use perceive it useful 
more than younger people. In addition, the current study demonstrates that age moderates the effect of security/privacy on PU in a way that it is stronger for older people than younger people (H16: $\beta=0.104, p<$ 0.05). This implies that as people age their security and privacy concerns become less important, this finding informs that younger people become less likely to observe and appreciate the usefulness of the technology. Previous empirical analysis has reported similar findings (Zukowski \& Brown, 2007; Hoofnagle et al., 2010; Walrave et al., 2012). The present analysis has confirmed that age moderates the relationship that connects cost with PEOU and PU in a way that as age increases the cost perceptions decrease (H18: $\beta=-0.129, \mathrm{p}<0.01, \mathrm{H} 19$ : $\beta=-0.088, \mathrm{p}<0.05$ ). These results are conflicting with the existing literature (Steele et al., 2009; Chen $\&$ Chan, 2011; Suki, 2011). However, this study shows that cost has no empirical significance on PEOU and PU. Still, though, unexpectedly the current findings strongly conclude that younger generations pay more emphasis on perceptions of cost than older generations.

In the light of the current research, seven hypotheses measuring the moderating influence of age are not supported (H12, H13, H14, H15, H17, H20, and H21). First, the effect of social influence on perceived usefulness and intention is not moderated by age (H13, H12). These findings imply that older people are not inclined to place greater emphasis on social needs as presumed in the current study. The results reported by this study are not in harmony with previous conclusions (Morris \& Venkatesh, 2000; Burton-Jones \& Hubona, 2006). Furthermore, the moderating effect of age of PEOU and PU constructs on BI construct to adopt m-healthcare are not supported (H20, H21). The current results inform that people, regardless to their age, have no variations in their perceptions of ease of use and usefulness toward intentions to use the technology. The results obtained here are unexpected since many empirical studies have yielded results that support the hypothesis assumed to hold true in the current study (Venkatesh et al., 2003; Wang et al., 2009, Cruz et al., 2010; Venkatesh et al., 2012).

The moderating impact of age on the relationships that link trust with PEOU and PU are found to be statistically non-significant (H15, H14). This indicates that people of different ages have similar perceptions concerning the effect of trust on PEOU and PU. These findings are not inline with conclusions of Peter and Valkenburg (2011) and Yao et al. (2007) who confirmed that older people were more wary of trusting new innovations, particularly online and mobile-based technologies. Zulman et al. (2011) also revealed that older people were largely the least to put much trust in the Internet channel for acquiring health information in comparison with younger people. In the meantime, the current result conforms to findings reported by Liébana-Cabanillas et al. (2014) in a study conducted on m-payment adoption. With respect to age-related differences, patients of different ages seem to have similar orientations towards the impact of security/privacy on PEOU (H17).

This study demonstrates that gender moderates the relationship between perceived ease of use and behavioral intention to adopt $m$-healthcare, the effect was more strongly for women than for men $(H 33: \beta=0.090, p<0.05)$. Similar conclusions were reported by Chiu et al. (2005) and Park et al. (2013) in the context of non-healthcare domains. Venkatesh et al. (2003) and Riquelme and Rios (2010) also arrived at similar results. The current result implies that women's PEOU influences BI more strongly than men. This finding can be explained since women generally exhibit a greater level of perceived difficulty than men when challenged by new innovation and also lack the confidence necessary to implement m-healthcare process in a simple and straightforward manner. Therefore, women become concerned about perceived ease of use as a vital predictor of the technology more than men.

This study hypothesized that women's perceptions of SI is higher on PU than men (H24). Unexpectedly and interestingly, the current findings demonstrated that the reverse of the conceptualized hypothesis was empirically supported, whereby the effect of SI on PU is higher for men than women (H24: $\beta=0.087, \mathrm{p}<0.05)$. However, previous conclusions reported different results (e.g., Venkatesh et al., 2003). Still, Terzis and Economides (2011) and Wang et al. (2009), in non-healthcare domains, have reported findings in harmony with current results. Apparently, men's patients seem to be more heavily exposed to their immediate environment than women's patients. Indeed, this is remarkable and yet unexpected conclusion. More, this study hypothesized that trust perceptions on PU are stronger for men than women $(\mathrm{H} 25)$. The findings obtained here have revealed that the reverse of this hypothesis held true $(\mathrm{H} 25: \beta=-0.076, \mathrm{p}<0.05)$. Thus, if the trust in m-healthcare systems increases women will tend to appreciate the usefulness of the system more strongly than men and the likelihood of women's BI to adopt the technology may increase. Similar findings were reported by Awad and Ragowsky (2008) in the environment of online channel. Besides, this research confirms that gender has some moderating effect on the relationships between cost and PEOU and PU (H30: $\beta=0.107, p<0.01, H 29: \beta=0.100, p<0.01)$. However, the current findings reveal that perception of cost has no statistical influence on PEOU and PU to adopt m-healthcare (H11 and H10). Even though, in accordance with current results, women are expected to give more emphasis on perceptions of cost than men. Similar results were concluded by Venkatesh et al. (2012). 
Regarding the moderating influence of gender on primary TAM-related relationships, this study reveals that gender has no impact on the relationships that connect PU with BI and PEOU with PU (H32, H31). These results are not in line with some prior research studies conducted on various IS/IT domains and settings (Venkatesh et al., 2003; Ong \& Lai, 2006; Shin, 2009; Pan \& Jordan-Marsh, 2010; Riquelme \& Rios, 2010; Van Slyke et al., 2010; Goh, 2011). The current findings point to that, as far as PU is concerned, both patients' genders are tuned to similar perceptions and orientations. Unlike PEOU which has been reported here to vary among different genders. Further, this study concludes that there are no variations in how different genders perceive the influence of PEOU on PU. Indeed, both genders believe equally that if the system is easy to use, therefore they perceive it useful. However, Venkatesh et al. (2003) and others (Ong \& Lai, 2006; Amin, 2007; Riquelme \& Rios, 2010) have concluded results contrasted with the current findings.

Furthermore, gender differences have no empirical influence on the relationship between SI and BI (H23). This indicates that both genders show no perceptual variations in relation to how SI affects BI. This study also failed to find any important moderating influence of gender on the link between trust and PEOU (H26). This indicates the impact of trust on PEOU is not influenced by gender variations. Similarly, the relationships that link security/privacy with PEOU and PU are not significantly moderated by gender (H28, H27). Thus, security and privacy issues are not influenced by gender differences in relation to the adoption of m-healthcare. However, literature has reported that women tend to be influenced more strongly by security and privacy issues than men (Fogel \& Nehmad, 2009; Wilkowska \& Ziefle, 2011; Michota, 2013).

\section{Contributions, Conclusions and Limitations}

\subsection{Theoretical Contributions}

The current empirical analysis makes many main theoretical contributions to literature. First, mobile healthcare is generally an unexplored field of research, particularly in developing countries. Therefore, the current analysis adds to the emerging literature on $\mathrm{m}$-healthcare technology the factors inline with patients' perceptions and perspectives that affect the adoption process of $\mathrm{m}$-healthcare. In addition, this work adds to the body of literature a consolidated model based on a well-founded theoretical base that allows furnishing appropriate hypotheses for better investigating the factors impacting the adoption process of mobile healthcare in Jordan. Indeed, better comprehension of m-healthcare phenomenon has been largely achieved. Second, the current study is one of the rare studies that has used an extended TAM theory in investigating $\mathrm{m}$-healthcare adoption. The final outcomes of this research offer considerable empirical evidence to back the applicability of the TAM model in a novel environment of $\mathrm{m}$-healthcare and a developing country environment. This is certainly an important contribution to current knowledge. Third, the current findings report that the perceptions of ease of use and usefulness are predominantly fundamental to predict the individuals' behavioral intention to use the technology. This investigation strengthens the significance of these determinants in the context of mobile healthcare. Further, social influence, trust, and security/ privacy factors are all important determinants to predict and explain both PEOU and PU constructs among patients, which lead to enhancement of behavioral intention. The findings of this study further emphasize the common perception that PEOU and PU constructs remain predominantly the most influential factors for determining the behavioral intention to adopt an innovation. In conclusion, these contributions are important in the sense that the current study has been launched in an emerging domain of m-healthcare and in a non-western culture. Fourth, in the context of this analysis, age difference has been empirically found to have some moderating influence on mobile healthcare adoption in Jordan. The current research has incorporated core constructs of TAM and some external variables that were presumed to influence the adoption process of m-healthcare, and the outcome of the current study informs that people of different age perceive some of the proposed relationships among these constructs differently. These are very important contributions to literature because a variety of marketing strategies can be developed in accordance with these outcomes to promote and enhance the adoption and diffusion of m-healthcare among patients. Finally, the current findings provide empirical significance that gender differences play a significant moderating role in $\mathrm{m}$-healthcare adoption among patients. The empirical evidence of this study suggests that there are variations among different genders in how they respond to relationships linking some of the constructs of the current model. The conclusions of the current study inform the literature on the importance of gender differences since genders are empirically found to follow different perceptions toward the adoption process of $\mathrm{m}$-technologies. These contributions are significant because the void in the literature regarding these types of conclusions is remarkable.

\subsection{Practical Implementation}

The findings obtained in the current analysis point to an interesting practical implications, these can be potentially critical for the benefits of improving the adoption of m-healthcare if appropriate strategies are 
effectively developed inline with these findings. First, the current study reinforces the importance of providing means or strategies by technology developers and providers that will result in achieving higher levels of perceptions of ease of use and usefulness of the technology since they are empirically established to hold crucial aspects of patients' intention toward technology adoption. Therefore, healthcare providers must work more collaboratively with others to prove patients with m-healthcare systems that are easy to use and useful, which may increase behavioral intention and subsequent actual use of the technology. Indeed, mobile devices are inherently constrained in their resources and having many limitations. Effectively, it is important that system interfaces are user-friendly and operating systems are agile, and that will significantly improve productivity and performance of patients in handling these technologies to better manage their own diseases. Second, social influence is a vital element in the context of the current study. Therefore, it is imperative that effective promotion strategies to be in place for exploiting considerations of social influence. Undoubtedly, it is worth taking advantage of the roles of social media and social networks in enhancing and facilitating the development of positive patients' perceptions toward adoption of m-healthcare. In addition, the potential of surrounding environment (i.e., family and peers) can be influential in triggering users' perceptions toward adoption behavior. Third, building trust mechanisms through implementing risk-reduction instruments in m-healthcare systems to motivate individuals in participating in the adoption of the technology have become a necessity in today's challenging and risky environment. Further, it is true that $\mathrm{m}$-healthcare is redefining security/privacy perimeters, and therefore adapting strategies that emphasize the importance of having security and privacy policy requirements are categorically crucial for providing a higher level of reassurance regarding the safeguard of patients' personnel data. These strategies, if implemented properly and adequately, would help patients perceive that $\mathrm{m}$-healthcare technology is trustworthy, secure, reliable, and safe, and this may eventually lead to a higher level of BI to adopt and use the technology. Finally, developing and implementing strategies of individuals' segmentation is extremely vital that based on demographic information of age and gender and inline with the current findings with respect to how age and gender moderate some of the proposed relationships. From patients' perspectives, this will generate more favorable perceptions, more motivational attitude and greater personnel satisfaction toward technology adoption (Liébana-Cabanillas et al., 2014), and in turn, will lead to higher pace of adoption.

\subsection{Conclusions}

The current study attempts to formulate a new model by incorporating additional parameters in a well-established TAM theory and implementing them to a novel context of m-healthcare in a developing country environment. In addition to the core constructs of the primary TAM (PEOU and PU), the social influence, trust, and security/privacy parameters are empirically influential in the process of making the decision to adopt m-healthcare technologies by consumers (patients). In addition, the TAM model is found to be applicable to $\mathrm{m}$-healthcare domain in a developing country and adaptable to a unique category of individuals such as patients. Nevertheless, this study surprisingly points out that cost perception is not an important aspect in the acceptance of m-healthcare technology among patients in Jordan. Further, the demographics of age and gender as moderators in this study are found to have some empirical significance on the adoption of $m$-healthcare technology.

\subsection{Limitations and Future Studies}

There exist several limitations associated with this research that might narrow the scope of the findings, and point to potential directions for future studies. For example, the integrated external factors in the current model may be inadequate to depict a full picture of the adoption process of m-healthcare in Jordan. Therefore, future research studies may include more variables such as risk perceptions, mobile self-efficacy, perceived anxiety, and perceived image, as well as additional demographic factors such as individual-level cultural values, experience, education level, and income. Further, the current study's theoretical model has not included the actual usage behavior; therefore, future studies may incorporate the influence of behavioral intention on actual use construct so that how much behavioral intentions are translated to actual use can be determined. Finally, the current study is cross-sectional by design, a longitudinal perspective may increase the possibility of understanding the temporal variations of individuals' perceptions toward adoption behavior of the technology.

\section{References}

Ahuja, M. K., Chudoba, K. M., Kacmar, C. J., McKnight, D. H., \& George, J. F. (2007). IT road warriors: Balancing work-family conflict, job autonomy, and work overload to mitigate turnover intentions. Mis Quarterly, 1-17.

Akter, S., Ray, P., \& D’Ambra, J. (2013). Continuance of m-Health services at the bottom of the pyramid: The 
roles of service quality and trust. Electronic Markets, 23(1), 29-47. http://dx.doi.org/10.1007/s12525-012-0091-5

Al-Fahad, F. N. (2009). Students' attitudes and perceptions towards the effectiveness of mobile learning in King Saud University, Saudi Arabia. The Turkish Online Journal of Educational Technology (TOJET), 8(2), 111-119.

Al-Jbour, B., Kamel, A. A., \& Barhoom, H. (2013). Knowledge about Hypertension and Antihypertensive Medication Compliance in a Jordanian Community Sample. Journal of Education and Practice, 4(24), 81-87.

Amin, H. (2007). Internet Banking Adoption among Young Intellectuals. Journal of Internet Banking and Commerce, 12(3), 1-13.

Ansary, O., \& Roushdy, A. (2013). Factors Affecting Egyptian Consumers' Intentions for Accepting Online Shopping. The Journal of American Academy of Business, Cambridge, 19(1), 191-201.

Arab Advisers Group. (2013). Retrieved from http://www.arabadvisors.com/Pressers/presser-230713.htm

Ashton, A. S., Scott, N., Solnet, D., \& Breakey, N. (2010). Hotel restaurant dining: The relationship between perceived value and intention to purchase. Tourism and Hospitality Research, 10(3), 206-218. http://dx.doi.org/10.1057/thr.2010.5

Au, N., Ngai, E. W., \& Cheng, T. E. (2008). Extending the understanding of end user information systems satisfaction formation: An equitable needs fulfillment model approach. MIS Quarterly, 43-66.

Avancha, S., Baxi, A., \& Kotz, D. (2012). Privacy in mobile technology for personal healthcare. ACM Computing Surveys (CSUR), 45(1), 3. http://dx.doi.org/10.1145/2379776.2379779

Awad, N. F., \& Ragowsky, A. (2008). Establishing trust in electronic commerce through online word of mouth: An examination across genders. Journal of Management Information Systems, 24(4), 101-121. http://dx.doi.org/10.2753/MIS0742-1222240404

Bakar, A., Rahim, A., \& Hashim, F. (2008). The determinants of online hotel reservations among university staffs. Communications of the IBIMA, 4, 13-21.

Banchs, J. E., Benvenuto, V., Baquero, G. A., Hess, S. L., Heron, K. E., LaPine, S., \& Curry, W. J. (2014). High Adoption Rates Of Mobile Technology By Cardiology Clinic Patients But Limited Use Of Health Applications. Journal of the American College of Cardiology, 63(12_S).

Bansal, G., Zahedi, F., \& Gefen, D. (2010). The impact of personal dispositions on information sensitivity, privacy concern and trust in disclosing health information online. Decision Support Systems, 49(2), $138-150$. http://dx.doi.org/10.1016/j.dss.2010.01.010

Basu, S., Andrews, J., Kishore, S., Panjabi, R., \& Stuckler, D. (2012). Comparative performance of private and public healthcare systems in low-and middle-income countries: A systematic review. PLoS Medicine, 9(6), http://dx.doi.org/10.1371/journal.pmed.1001244

Beckers Hospital Review. (March, 2014). Potential Data Breaches Most Significant Barrier to mHealth Adoption: Survey Finds. Retrieved from http://www.beckershospitalreview.com/healthcare-information-technology/potential-data-breaches-most-sig nificant-barrier-to-mhealth-adoption-survey-finds.html

Bigne, E., Ruiz, C., \& Sanz, S. (2005). The impact of internet user shopping patterns and demographics on consumer mobile buying behaviour. Journal of Electronic Commerce Research, 6(3), 193-209.

Burton-Jones, A., \& Hubona, G. S. (2006). The mediation of external variables in the technology acceptance model. Information \& Management, 43(6), 706-717. http://dx.doi.org/10.1016/j.im.2006.03.007

Calisir, F., Gumussoy, C. A., \& Bayram, A. (2009). Predicting the behavioral intention to use enterprise resource planning systems: An exploratory extension of the technology acceptance model. Management Research News, 32(7), 597-613. http://dx.doi.org/10.1108/01409170910965215

Castle, E., Eisenberger, N. I., Seeman, T. E., Moons, W. G., Boggero, I. A., Grinblatt, M. S., \& Taylor, S. E. (2012). Neural and behavioral bases of age differences in perceptions of trust. Proceedings of the National Academy of Sciences, 109(51), 20848-20852. http://dx.doi.org/10.1073/pnas.1218518109

Cenfetelli, R., \& Bassellier, G. (2009). Interpretation of formative measurement in information systems research. MIS Quarterly, 33(4), 689-708. 
Chandra, A., \& Skinner, J. (2012). Technology Growth and Expenditure Growth in Health Care. Journal of Economic Literature, 50(3), 645-680. http://dx.doi.org/10.1257/jel.50.3.645

Chang, E., Thomson, P., Dillon, T., \& Hussain, F. (2005). The fuzzy and dynamic nature of trust. In Trust, Privacy, and Security in Digital Business (pp. 161-174). Springer Berlin Heidelberg. http://dx.doi.org/10.1007/11537878_17

Chau, P. Y. K., Hu, P. J. H., Lee, B. L. P., \& Au, A. K. K. (2007). Examining customers' trust in online vendors and dropouts: An empirical study. Electronic Commerce Research and Applications, 6(2), 171-182. http://dx.doi.org/10.1016/j.elerap.2006.11.008

Chen, K., \& Chan, A. H. S. (2011). A review of technology acceptance by older adults. Gerontechnology, 10(1), 1-12. http://dx.doi.org/10.4017/gt.2011.10.01.006.00

Cheung, C. M., \& Lee, M. K. (2011). Exploring the Gender Differences in Student Acceptance of an Internet-Based Learning Medium. In Technology Acceptance in Education (pp. 183-199). SensePublishers. http://dx.doi.org/10.1007/978-94-6091-487-4_10

Chiarini, G., Ray, P., Akter, S., Masella, C. \& Ganz, A. (2013). mHealth technologies for chronic diseases and elders: A systematic review. IEEE Journal on Selected Areas in Communications, 31(9), 6-18. http://dx.doi.org/10.1109/JSAC.2013.SUP.0513001

Chib, A., Van Velthoven, M. H., \& Car, J. (2014). Health adoption in low-resource environments: A review of the use of mobile healthcare in developing countries. Journal of Health Communication, (ahead-of-print), 1-53.

Chin, W. W., Marcolin, B. L., \& Newsted, P. R. (2003). A Partial Least Squares Latent Variable Modeling Approach for Measuring Interaction Effects: Results from a Monte Carlo Simulation Study and an Electronic-Mail Emotion/Adoption Study. Information Systems Research, 14(2), 189-217. http://dx.doi.org/10.1287/isre.14.2.189.16018

Chiu, Y. B., Lin, C. P., \& Tang, L. L. (2005). Gender differs: Assessing a model of online purchase intentions in e-tail service. International Journal of Service Industry Management, 16(5), 416-435. http://dx.doi.org/10.1108/09564230510625741

Cho, H., \& Jialin, S. K. (2008). Influence of gender on Internet commerce: An explorative study in Singapore. Journal of Internet Commerce, 7(1), 95-119. http://dx.doi.org/10.1080/15332860802004394

Cho, H., Rivera-Sánchez, M., \& Lim, S. S. (2009). A multinational study on online privacy: Global concerns and local responses. New Media \& Society, 11(3), 395-416. http://dx.doi.org/10.1177/1461444808101618

Choi, S. (2010), Exploring intention to adopt mobile TV service in the USA: Toward a new model with cognitive-based and emotional-based constructs (Thesis). University of South Carolina.

Chong, A. Y. L. (2013). Mobile commerce usage activities: The roles of demographic and motivation variables. Technological Forecasting and Social Change, 80(7), 1350-1359. http://dx.doi.org/10.1016/j.techfore.2012.12.011

Chong, A. Y. L., Chan, F. T., \& Ooi, K. B. (2012). Predicting consumer decisions to adopt mobile commerce: Cross country empirical examination between China and Malaysia. Decision Support Systems, 53(1), 34-43. http://dx.doi.org/10.1016/j.dss.2011.12.001

Chung, J. E., Park, N., Wang, H., Fulk, J. \& McLaughlin, M. (2010) Age differences in perceptions of online community participation among non-users: An extension of the Technology Acceptance Model. Computers in Human Behavior, 26(6), 1674-1684. http://dx.doi.org/10.1016/j.chb.2010.06.016

Conklin, T. P. (2002). Health Care in the United States: An Evolving System. Michigan Family Review, 7(1).

Cresswell, K., \& Sheikh, A. (2012). Organizational issues in the implementation and adoption of health information technology innovations: An interpretative review. International Journal of Medical Informatics, 82(5), 73-86. http://dx.doi.org/10.1016/j.ijmedinf.2012.10.007

Cruz, P., Neto, L. B. F., Muñoz-Gallego, P., \& Laukkanen, T. (2010). Mobile banking rollout in emerging markets: Evidence from Brazil. International Journal of Bank Marketing, 28(5), 342-371. http://dx.doi.org/10.1108/02652321011064881

Cutler, S. J., Hendricks, J., \& Guyer, A. (2003). Age differences in home computer availability and use. The Journals of Gerontology Series B: Psychological Sciences and Social Sciences, 58(5), 271-280. http://dx.doi.org/10.1093/geronb/58.5.S271 
Cyr, D., \& Bonanni, C. (2005). Gender and website design in e-business. International Journal of Electronic Business, 3(6), 565-582. http://dx.doi.org/10.1504/IJEB.2005.008536

Czaja, S. J., \& Lee, C. C. (2007). Information technology and older adults. In J. A. Jacko, \& A. Sears (Eds.), The human-computer interaction handbook (2nd ed., pp. 777-792). New York: Erlbaum. http://dx.doi.org/10.1201/9781410615862.ch39

Czaja, S. J., Sharit, J., Lee, C. C., Nair, S. N., Hernández, M. A., Arana, N., \& Fu, S. H. (2013). Factors influencing use of an e-health website in a community sample of older adults. Journal of the American Medical Informatics Association, 20(2), 277-284. http://dx.doi.org/10.1136/amiajnl-2012-000876

Dadgar, M., Samhan, B., Joshi, K. D. (2013). Mobile Health Information Technology and Patient Care: A Literature Review and Analysis. 19th Americas Conference on Information Systems, Chicago, Illinois, USA.

Davis, F. D. (1989). Perceived usefulness, perceived ease of use, and user acceptance of information technology. MIS Quarterly, 319-340. http://dx.doi.org/10.1287/mnsc.35.8.982

Davis, F. D., Bagozzi, R. P., Warshaw, P. R. (1989). User acceptance of computer technology: A comparison of two theoretical models. Manage. Sci., 35(8), 982-1003.

Davis, F., \& Venkatesh, D. (1995). Measuring user acceptance of emerging information technologies: An assessment of possible method biases. In 28th Annual Hawaii International Conference on System Sciences, Hawaii, pp. 729-736. Los Alamitos, Calif: IEEE Computer Society Press. http://dx.doi.org/10.2307/249008

Deloitte. (2014). Global health care outlook: Shared challenges. Retrieved from https://www2.deloitte.com/content/dam/Deloitte/global/Documents/Life-Sciences-Health-Care/dttl-lshc-20 14-global-health-care-sector-report.pdf

Dennis, C., Morgan, A., Wright, L. T., \& Jayawardhena, C. (2010). The influences of social e-shopping in enhancing young women's online shopping behaviour. Journal of Customer Behaviour, 9(2), 151-174. http://dx.doi.org/10.1362/147539210X511353

Dong, J. Q., \& Zhang, X. (2011). Gender differences in adoption of information systems: New findings from China. Computers in Human Behavior, 27(1), 384-390. http://dx.doi.org/10.1016/j.chb.2010.08.017

Dutta, S., \& Bilbao-Osorio, B. (Eds.). (2012). Global information technology report: Living in a hyperconnected world. Geneva: World Economic Forum and INSEAD.

Europe-mHealth (mobile health) (2013). Key to improving EU healthcare systems. International Journal of Health Care Quality Assurance, 26(8).

Eze, U. C., Goh, M. H., Ling, H. Y., \& Lee, C. H. (2011). Intention to use e-government services in Malaysia: Perspective of individual users. In Informatics Engineering and Information Science (pp. 512-526). Springer Berlin Heidelberg. http://dx.doi.org/10.1007/978-3-642-25453-6_43

Fan, Y., \& Miao, Y. (2012). Effect of Electronic Word-of-Mouth on Consumer Purchase Intention: The Perspective of Gender Differences. International Journal of Electronic Business Management, 10(3), 175-181.

Faqih, K. (2013). Exploring the Influence of Perceived Risk and Internet Self-efficacy on Consumer Online Shopping Intentions: Perspective of Technology Acceptance Model. International Management Review, 9(1), 69-78.

Faqih, K. M. S. (2011). Integrating perceived risk and trust with technology acceptance model: An empirical assessment of customers' acceptance of online shopping in Jordan. In 2011 International Conference on Research and Innovation in Information Systems (ICRIIS), pp. 1-5. http://dx.doi.org/10.1109/ICRIIS.2011.6125686

Faqih, K. M. S., \& Jaradat, M. I. R. M. (2014). Assessing the moderating effect of gender differences and individualism-collectivism at collectivism at individual-level on the adoption of mobile commerce technology: TAM3 perspective. Journal of Retailing and Consumer Services, 22(1), 37-52. http://dx.doi.org/10.1016/j.jretconser.2014.09.006i,

Farzandipour, M., Sadoughi, F., Ahmadi, M., \& Karimi, I. (2010). Security requirements and solutions in electronic health records: Lessons learned from a comparative study. Journal of Medical Systems, 34(4), 629-642. http://dx.doi.org/10.1007/s10916-009-9276-7 
Fernández-Alemán, J. L., Señor, I. C., Lozoya, P. Á. O., \& Toval, A. (2013). Security and privacy in electronic health records: A systematic literature review. Journal of Biomedical Informatics, 46(3), 541-562. http://dx.doi.org/10.1016/j.jbi.2012.12.003

Fogel, J., \& Nehmad, E. (2009). Internet social network communities: Risk taking, trust, and privacy concerns. Computers in Human Behavior, 25(1), 153-160. http://dx.doi.org/10.1016/j.chb.2008.08.006

Fogel, J., Ribisl, K. M., Morgan, P. D., Humphreys, K., \& Lyons, E. J. (2008). The underrepresentation of African Americans in online cancer support groups. Journal of the National Medical Association, 100(6), 705-712.

Fonchamnyo, D. C. (2013). Customers' Perception of E-banking Adoption in Cameroon: An Empirical Assessment of an Extended TAM. International Journal of Economics \& Finance, 5(1).

Fornell, C., \& Larcker, F. L. (1981). Evaluating Structural Equation Models with Unobservable Variables and Measurement Error. Journal of Marketing Research, 18, 39-50. http://dx.doi.org/10.2307/3151312

Garg, A. K., \& Garg, D. (2013). An Assessment of 3G Internet Service Acceptance in Botswana: Technology Acceptance Model with Social Influence and Price Perception. Pakistan Journal of Social Sciences (PJSS), 33(1), 47-60.

Gefen, D., \& Straub, D. W. (1997). Gender difference in the perception and use of e-mail: An extension to the technology acceptance model. MIS Quarterly, 21(4), 389-401. http://dx.doi.org/10.2307/249720

Gefen, D., Karahanna, E., \& Straub, D. W. (2003). Trust and TAM in online shopping: An integrated model. MIS Quarterly, 27(1), 51-90.

GNRD News. (2014). Retrieved from http://gnrd.net/seemore.php?id=277

Goffee, R., \& Jones, G. (1996). What holds the modern company together? Harvard Business Review, 74, 133-148.

Goh, T. T. (2011). Exploring Gender Differences in SMS-Based Mobile Library Search System Adoption. Educational Technology and Society, 14(4), 192-206.

Gurau, C., \& Ranchhod, A. (2009). Consumer privacy issues in mobile commerce: A comparative study of British, French and Romanian consumers. The Journal of Consumer Marketing, 26(7), 496-507. http://dx.doi.org/10.1108/07363760911001556

Gurman, T. A., Rubin, S. E., \& Roess, A. A. (2012). Effectiveness of mHealth behavior change communication interventions in developing countries: A systematic review of the literature. Journal of Health Communication, 17(sup1), 82-104. http://dx.doi.org/10.1080/10810730.2011.649160

Ha, H., \& Akamavi, R. K. (2009). Does trust really matters in electronic shopping? A comparative study of Korean, Taiwanese and UK customers. Seoul Journal of Business, 15(1), 92-119.

Haederle, M. (2011). Technology fear stops older adults from logging on. AARP Bulletin. Retrieved from http://www.aarp.org/technology/innovations/info-08-2011/elderly-fearof-technology.html

Hair, J. F., Black, W. C., Babin, B. J., \& Anderson, R. E. (2009). Multivariate data analysis. Upper Saddle River, NJ: Prentice Hall.

Hair, J. F., Sarstedt, M., Pieper, T. M., \& Ringle, C. M. (2012). The Use of Partial Least Squares Structural Equation Modeling in Strategic Management Research: A Review of Past Practices and Recommendations for Future Applications. Long Range Planning, 45, 320-340. http://dx.doi.org/10.1016/j.lrp.2012.09.008

Hair, J., Babin, B., Money, A., \& Samouel, P. (2003). Essentials of Business Research Methods. New York: John Wiley \& Sons Inc.

Hamza, A., \& Shah A. (2014). Gender and mobile payment system adoption among students of tertiary institutions in Nigeria. International Journal of Computer and Information Technology, 3(1).

Harbour, J., \& Chowdhury, G. G. (2007). Use and outcome of online health information services: A study among $\begin{array}{llll}\text { Scottish population. Journal of 229-242. } & \text { Documentation, 63(2), }\end{array}$ http://dx.doi.org/10.1108/00220410710737196

Hasan, B. (2010). Exploring gender differences in online shopping attitude. Computers in Human Behavior, 26(4), 597-601. http://dx.doi.org/10.1016/j.chb.2009.12.012

Hernandez, B., Jiménez, J., \& Martín, M. J. (2011). Age, gender and income: Do they really moderate online 
shopping behaviour? Online Information Review, 35(1), 113-133. http://dx.doi.org/10.1108/14684521111113614

Hill, C., Zurakowski, D., Bennet, J., Walker-White, R., Osman, J. L., Quarles, A., \& Oriol, N. (2012). Knowledgeable Neighbors: A mobile clinic model for disease prevention and screening in underserved communities. American Journal of Public Health, 102(3), 406-410. http://dx.doi.org/10.2105/AJPH.2011.300472

Hill, R., Beynon-Davies, P., \& Williams, M. D. (2008). Older people and internet engagement: Acknowledging social moderators of internet adoption, access and use. Information Technology \& People, 21(3), 244-266. http://dx.doi.org/10.1108/09593840810896019

Holden, R. J., \& Karsh, B. (2010). The technology acceptance model: Its past and its future in health care. Journal of Biomedical Informatics, 43(1), 159-172. http://dx.doi.org/10.1016/j.jbi.2009.07.002

Hoofnagle, C., King, J., Li, S., \& Turow, J. (2010). How different are young adults from older adults when it comes to information privacy attitudes and policies? University of California, Berkeley. Retrieved from http://papers.ssrn.com/sol3/papers.cfm?abstract_id=1589864

Hsieh, J. P. A., Rai, A., \& Keil, M. (2008). Understanding digital inequality: Comparing continued use behavioral models of the socio-economically advantaged and disadvantaged. MIS Quarterly, 97-126. Retrieved from http://www.marketresearchmoz.com/ict/the-mobile-healthcare-mhealth-bible-175332.pdf

Hung, M. C., \& Jen, W. Y. (2012). The adoption of mobile health management services: An empirical study. Journal of Medical Systems, 36(3), 1381-1388. http://dx.doi.org/10.1007/s10916-010-9600-2

Hung, S. Y., \& Chang, C. M. (2005). User acceptance of WAP services: test of competing theories. Computer Standards and Interfaces, 27(4), 359-370. http://dx.doi.org/10.1016/j.csi.2004.10.004

Hung, S. Y., Ku, C. Y., \& Chang, C. M. (2003). Critical factors of WAP services adoption: An empirical study. $\begin{array}{llll}\text { Electronic } \quad \text { Commerce } & \text { Research andications, }\end{array}$ http://dx.doi.org/10.1016/S1567-4223(03)00008-5

Hwang, Y. (2010). The moderating effects of gender on e-commerce systems adoption factors: An empirical investigation. Computers in Human Behavior, 26, 1753-1760. http://dx.doi.org/10.1016/j.chb.2010.07.002

ICT Market. (2012). Trends, Analysis \& Statistics. Retrieved from http://www.reportlinker.com/report/best/keywords/ict?utm_source=adwords2\&utm_medium=cpc\&utm_ca mpaign=High_tech_and_Media_ROW\&utm_adgroup=Ict_ROW\&gclid=CKPSqLPovrcCFczC3godh2QAK $\mathrm{g}$

Istepanian, R., Laxminarayan, S., \& Pattichis, C. S. (2006). Mhealth. Springer Science Business Media Incorporated. http://dx.doi.org/10.1007/b137697

Jaradat, M. I. R. M. (2014). Understanding individuals' perceptions, determinants and the moderating effects of age and gender on the adoption of mobile learning: Developing country perspective. International Journal of Mobile Learning and Organisation, 8(3-4), 253-275. http://dx.doi.org/10.1504/IJMLO.2014.067028

Jaradat, M. I. R. M., \& Smadi, Z. M. D. A. (2013). Applying the technology acceptance model to the introduction of mobile healthcare information systems. International Journal of Behavioural and Healthcare Research, 4(2), 123-143. http://dx.doi.org/10.1504/IJBHR.2013.057363

Jaradat, M. I., \& Faqih, K. M. (2014). Investigating the Moderating Effects of Gender and Self-Efficacy in the Context of Mobile Payment Adoption: A Developing Country Perspective. International Journal of Business and Management, 9(11), 147-169. http://dx.doi.org/10.5539/ijbm.v9n11p147

Jen, W. Y., \& Hung, M. C. (2010). An empirical study of adopting mobile healthcare service: The family' s perspective on the healthcare needs of their elderly members. Telemedicine and e-Health, 16(1), 41-48. http://dx.doi.org/10.1089/tmj.2009.0093

Jensen, C., Potts, C., \& Jensen, C. (2005). Privacy practices of Internet users: Self-reports versus observed behavior. International Journal of Human-Computer Studies, 63(2), 203-227. http://dx.doi.org/10.1016/j.ijhcs.2005.04.019

José, M. O. E., \& María, V. R. G. (2011). Explaining physicians' acceptance of EHCR systems: An extension of tam with trust and risk factors. Computers in Human Behaviour, 27(1), 319-332. http://dx.doi.org/10.1016/j.chb.2010.08.010 
Kaplan, B., \& Litwka, S. (2008). Ethical challenges of telemedicine and telehealth. Cambridge Quarterly of Healthcare Ethics, 17(4), 401-416. http://dx.doi.org/10.1017/S0963180108080535

Kaur, M., Sodhi, S. K., Kaur, P., Singh, J., \& Kumar, R. (2013). Gender differences in health care seeking behavior of tuberculosis patients in chandigarh. Indian J Tuberc, 60, 217-222.

Kim, H. W, Chan, H. C., \& Gupta, S. (2007) Value-based Adoption of Mobile Internet: An empirical investigation, Decision Support Systems, 43, 111-126. http://dx.doi.org/10.1016/j.dss.2005.05.009

Klein, R. (2007). An empirical examination of patient-physician portal acceptance. European Journal of Information Systems, 16(6), 751-760. http://dx.doi.org/10.1057/palgrave.ejis.3000719

Kock, N. (2013). WarpPLS 4.0 User Manual, ScriptWarp Systems, Laredo Texas. Retrieved from http://www.scriptwarp.com/ warppls/UserManual.pdf

Koenig-Lewis, N., Palmer, A., \& Moll, A. (2010). Predicting young consumers' take up of mobile banking services. International Journal of Bank Marketing, 28(5), 410-432. http://dx.doi.org/10.1108/02652321011064917

Kowalewski, S., Wilkowska, W., \& Ziefle, M. (2012). Accounting for user diversity in the acceptance of medical assistive technologies. In Electronic Healthcare (pp. 175-183). Springer Berlin Heidelberg.

Kuo, F. Y., Tseng, C. Y., Tseng, F. C., \& Lin, C. S. (2013). A Study of Social Information Control Affordances and Gender Difference in Facebook Self-Presentation. Cyberpsychology, Behavior, and Social Networking, 16(9), 635-644. http://dx.doi.org/10.1089/cyber.2012.0345

Lallmahamood, M. (2007). An Examination of Individual's Perceived Security and Privacy of the Internet in Malaysia and the Influence of this on their Intention to Use E-commerce: Using an Extension of the Technology Acceptance Model. Doctoral dissertation, Malaysian Institute of Management.

Laukkanen, T., \& Pasanen, M. (2008). Mobile banking innovators and early adopters: How they differ from other online users \& quest. Journal of Financial Services Marketing, 13(2), 86-94. http://dx.doi.org/10.1057/palgrave.fsm.4760077

Lee, C. H., Eze, U. C., \& Ndubisi, N. (2011). Analyzing key determinants of online repurchase intentions. Asia Pacific Journal of Marketing and Logistics, 23(2), 200-221. http://dx.doi.org/10.1108/13555851111120498

Lee, R. D., \& Mason, A. (Eds.). (2011). Population aging and the generational economy: A global perspective. Edward Elgar Publishing. http://dx.doi.org/10.4337/9780857930583

Leischow, S. J., Best, A., Trochim, W. M., Clark, P. I., Gallagher, R. S., Marcus, S. E., \& Matthews, E. (2008). Systems thinking to improve the public's health. American Journal of Preventive Medicine, 35(2), S196-S203. http://dx.doi.org/10.1016/j.amepre.2008.05.014

Li, H., \& Lai, M. M. (2011). Demographic differences and internet banking acceptance. MIS Review, 16(2), 55-92.

Li, J., Talaei-Khoei, A., Seale, H., Ray, P., \& MacIntyre, C. R. (2013). Health care provider adoption of ehealth: Systematic literature review. Interactive Journal of Medical Research, 2(1).

Liao, C. H., Tsou, C. W., \& Huang, M. F. (2007). Factors influencing the usage of 3G mobile services in Taiwan. Online Information Review, 31(6), 759-774. http://dx.doi.org/10.1108/14684520710841757

Liao, Q. V., \& Fu, W. T. (2014). Age differences in credibility judgments of online health information. ACM Transactions on Computer-Human Interaction (TOCHI), 21(1),

Lichtenstein, S., \& Williamson, K. (2006). Understanding consumer adoption of internet banking: An interpretive study in the Australian banking context. Journal of Electronic Commerce Research, 7(2), 50-66. http://dx.doi.org/10.1108/IMDS-03-2013-0137

Liébana-Cabanillas, F. J., Sánchez-Fernández, J., \& Muñoz-Leiva, F. (2014). Role of gender on acceptance of mobile payment. Industrial Management \& Data Systems, 114(2), 220-240.

Limayem, M., Hirt, S. G., \& Cheung, C. M. K. (2007). How habit limits the predictive power of intention: The case of information systems continuance. MIS Quarterly, 31(4), 705-737. http://dx.doi.org/10.1109/HICSS.2002.994223

Lin, S. P. (2011). Determinants of adoption of mobile healthcare service. International Journal of Mobile Communications, 9(3), 298-315. http://dx.doi.org/10.1504/IJMC.2011.040608 
Lin, S., \& Wu, S. (2002). Exploring the impact of online service quality on portal site usage. Proceedings of the 35th Hawaii International Conference on System Sciences, IEEE.

Lip-Sam, T., \& Hock-Eam, L. (2011). Estimating the determinants of B2B e-commerce adoption among small \& medium enterprises. International Journal of Business and Society, 12(1), 15-30.

Liu, L. S., Shih, P. C., \& Hayes, G. R. (2011). Barriers to the adoption and use of personal health record systems. In: Proc of iConference, pp. 363-370. http://dx.doi.org/10.1145/1940761.1940811

Lu, J., Yu, C. S., \& Liu, C. (2009). Mobile Data Service Demographics in Urban China. Journal of Computer Information Systems, 50(2).

Luarn, P., \& Lin, H. (2005). Toward an understanding of the behavioral intention to use mobile banking. Computers in Human Behavior, 21(6), 873-891. http://dx.doi.org/10.1016/j.chb.2004.03.003

Ma, Q., \& Liu, L. (2004). The technology acceptance model: A meta-analysis of empirical findings. Journal of Organizational and End User Computing (JOEUC), 16(1), 59-72. http://dx.doi.org/10.4018/joeuc.2004010104

Mallenius, S., Rossi, M., \& Tuunainen, V. K. (2007). Factors affecting the adoption and use of mobile devices and services by elderly people-results from a pilot study. 6th Annual Global Mobility Roundtable, 31.

Market Research Moz. (2013). The Mobile Healthcare (mHealth) Bible: 2014-2020.

Marshall, C., Lewis, D., \& Whittaker, M. (2013). mHealth technologies in developing countries: A feasibility assessment and a proposed framework. Retrieved from http://www.uq.edu.au/hishub/docs/WP25/WP25\%20mHealth_web.pdf

Mayernik, D., Resick, L., Skomo, M., \& Mandock, K. (2010). Parish nurse-initiated interdisciplinary mobile health care delivery project. JOGNN: Journal of Obstetric, Gynecologic \& Neonatal Nursing, 39(2), 227-234. http://dx.doi.org/10.1111/j.1552-6909.2010.01112.x

Mcknight, D. H., Carter, M., Thatcher, J. B., \& Clay, P. F. (2011). Trust in a specific technology: An investigation of its components and measures. ACM Transactions on Management Information Systems (TMIS), 2(2), 12. http://dx.doi.org/10.1145/1985347.1985353

Medical Economics. (2014). Cost still a barrier for mobile adoption in healthcare. Retrieved from http://medicaleconomics.modernmedicine.com/medical-economics/news/cost-still-barrier-mobile-adoptionhealthcare?page $=$ full

Michota, A. (2013). Digital security concerns and threats facing women entrepreneurs. Journal of Innovation and Entrepreneurship, 2(1), 1-11. http://dx.doi.org/10.1186/2192-5372-2-7

Mobihealthnews. (2014). Retrieved from http://mobihealthnews.com/28844/deloittes-four-ps-for-mobile-health-best-practices/

Mohamed, A. H. H., Tawfik, H., Al-Jumeily, D., \& Norton, L. (2011). MoHTAM: A technology acceptance model for mobile health applications. In Developments in E-systems Engineering (DeSE), pp. 13-18. http://dx.doi.org/10.1109/DeSE.2011.79

Morris, M. G., \& Venkatesh, V. (2000). Age differences in technology adoption decisions: Implications for a $\begin{array}{llll}\text { changing work force. Personnel } & \text { 375-403. }\end{array}$ http://dx.doi.org/10.1111/j.1744-6570.2000.tb00206.x

Napoli, P. M., \& Obar, J. A. (2013). Mobile Leapfrogging and Digital Divide Policy: Assessing the limitations of mobile Internet access. Fordham University Schools of Business Research Paper, (2263800). http://dx.doi.org/10.2139/ssrn.2263800

Nasri, W., Lanouar, C., \& Allagui, A. (2013). Expanding the Technology Acceptance Model to Examine Internet Banking Adoption in Tunisia Country. International Journal of Innovation in the Digital Economy (IJIDE), 4(4), 61-81. http://dx.doi.org/10.4018/ijide.2013100104

Nulty, D. (2008). The adequacy of response rates to online and paper surveys: What can be done? Assessment \& Evaluation in Higher Education, 33(3), 301-314. http://dx.doi.org/10.1080/02602930701293231

Ong, C. S., \& Lai, J. Y. (2006). Gender differences in perceptions and relationships among dominants of e-learning acceptance. Computers in Human Behavior, 22(5), 816-829. http://dx.doi.org/10.1016/j.chb.2004.03.006

Pan, S., \& Jordan-Marsh, M. (2010). Internet use intention and adoption among Chinese older adults: From the 
expanded technology acceptance model perspective. Computers in human behavior, 26(5), 1111-1119. http://dx.doi.org/10.1016/j.chb.2010.03.015

Park, C., Kim, D. G., \& Kim, C. (2013). Adoption of Short Message Service: Gender Difference. Issues in Information Systems, 14(1), 10-20.

Parker, R., \& Parrott, R. (1995). Patterns of self-disclosure across social support networks: Elderly, middle-aged, and young adults. The International Journal of Aging \& Human Development, 41, 281-297. http://dx.doi.org/10.2190/N9PC-CKMD-JKRR-1VJM

Passyn, K. A., Diriker, M., \& Settle, R. B. (2011). Images of online versus store shopping: Have the attitudes of men and woman, young and old really changed? Journal of Business \& Economics Research, 9(1), 99-110.

Pavlou, P. A., \& El Sawy, O. A. (2006). From IT leveraging competence to competitive advantage in turbulent environments: The case of new product development. Information Systems Research, 17(3), 198-227. http://dx.doi.org/10.1287/isre.1060.0094

Pavlou, P. A., \& Fygenson, M. (2006). Understanding and predicting electronic commerce adoption: An extension of the theory of planned behavior. MIS Quarterly, 115-143.

Payton, F. C., \& Kiwanuka-Tondo, J. (2009). Contemplating public policy in HIV/AIDS online content, then where is the technology spirit\&quest. European Journal of Information Systems, 18(3), 192-204. http://dx.doi.org/10.1057/ejis.2009.16

Peter, J., \& Valkenburg, P. M. (2011). Adolescents' online privacy: Toward a developmental perspective. In Privacy online (pp. 221-234). Springer Berlin Heidelberg. http://dx.doi.org/10.1007/978-3-642-21521-6_16

Phan, K., \& Daim, T. (2011). Exploring technology acceptance for mobile services. Journal of Industrial Engineering and Management, 4(2), 339-360. http://dx.doi.org/10.3926/jiem.2011.v4n2.p339-360

Porter, C. E., \& Donthu, N. (2006). Using the technology acceptance model to explain how attitudes determine Internet usage: The role of perceived access barriers and demographics. Journal of Business Research, 59(9), 999-1007. http://dx.doi.org/10.1016/j.jbusres.2006.06.003

Puschel, J., Mazzon, J. A. \& Hernandez, J. M. (2010). Mobile banking: Proposition of an Integrated Adoption Intention Framework. International Journal of Bank Marketing, 28(5), 389-409. http://dx.doi.org/10.1108/02652321011064908

Raghupathi, W., \& Tan, J. (2008). Information Systems and Healthcare XXX: Charting a Strategic Path for Health Information Technology. Communications of AIS, 2008(23), 501-522.

Reid, M., \& Levy, Y. (2008). Integrating trust and computer self-efficacy with TAM: An empirical assessment of customers' acceptance of banking information systems (BIS) in Jamaica. Journal of Internet Banking and Commerce, 12(3), 2008-2012.

Richter, N. F., Cepeda, G., Roldán, J. L., \& Ringle, C. M. (2015). European Management Research Using Partial Least Squares Structural Equation Modeling (PLS-SEM). European Management Journal (EMJ). http://dx.doi.org/10.1016/j.emj.2014.12.001

Riquelme, H. E., \& Rios, R. E. (2010). The moderating effect of gender in the adoption of mobile banking. International Journal of Bank Marketing, 28(5), 328-341. http://dx.doi.org/10.1108/02652321011064872

Royal Scientific Society. (2013).Retrieved from http://www.rss.jo/news/1081

Samhan, B., Dadgar, M., \& Joshi, K. D. (2013). Mobile Health Information Technology and Patient Care: Methods, Themes, and Research Gaps. ICHITA-2013 TRANSACTIONS, 18.

San Martín Gutiérrez, S., López-Catalán, B., \& Ramon-Jeronimo, M. A. (2012). Determinants of involvement in mobile commerce: The moderating role of gender. EsicMarket Economic and Business Journal, 141, 69-101.

Santos, C. P. D., \& Fernandes, D. V. D. H. (2011). Perceptions of justice after recovery efforts in internet purchasing: The impact on consumer trust and loyalty toward retailing sites and online shopping in general. BAR-Brazilian Administration Review, 8(3), 225-246. http://dx.doi.org/10.1590/S1807-76922011000300002

Sekaran, U. (2006). Research Methods for Business a Skill-Building Approach (4th ed.). New Delhi: John Wiley and Sons.

Sharif, M. S., Shao, B., Xiao, F., \& Saif, M. K. (2014). The Impact of Psychological Factors on Consumers Trust in Adoption of M-Commerce. International Business Research, 7(5), 148. 
http://dx.doi.org/10.5539/ibr.v7n5p148

Shi, W., Wu, P., Zhou, W., \& Chen, J. (2009). Gender differences in purchase intention on mobile data services. In Computational Sciences and Optimization, 2009. CSO 2009. International Joint Conference on (Vol. 1, pp. 773-777). http://dx.doi.org/10.1109/CSO.2009.71

Shin, D. H. (2007). User acceptance of mobile Internet: Implication for convergence technologies. Interacting with Computers, 19(4), 472-483. http://dx.doi.org/10.1016/j.intcom.2007.04.001

Shin, D. H. (2009). Towards an understanding of the consumer acceptance of mobile Wallet. Computers in Human Behavior, (25), 1343-1354. http://dx.doi.org/10.1016/j.chb.2009.06.001

Sorber, J. M., Shin, M., Peterson, R., \& Kotz, D. (2012, June). Plug-n-trust: Practical trusted sensing for mhealth. In Proceedings of the 10th international conference on Mobile systems, applications, and services (pp. 309-322). ACM. http://dx.doi.org/10.1145/2307636.2307665

Steele, R., Lo, A., Secombe, C., \& Wong, Y. K. (2009). Elderly persons' perception and acceptance of using wireless sensor networks to assist healthcare. International Journal of Medical Informatics, 78(12), 788-801. http://dx.doi.org/10.1016/j.ijmedinf.2009.08.001

Steinhubl, S. R., Muse, E. D., \& Topol, E. J. (2013). Can mobile health technologies transform health care? JAMA, 310(22), 2395-2396. http://dx.doi.org/10.1001/jama.2013.281078

Suki, N. M. (2011). Gender, Age, and Education: Do They Really Moderate Online Music Acceptance? Communications. http://dx.doi.org/10.5171/2011.959384

Sun, J., Fang, Y., \& Zhu, X. (2010). Privacy and emergency response in e-healthcare leveraging wireless body sensor networks. Wireless Communications, IEEE, 17(1), 66-73. http://dx.doi.org/10.1109/MWC.2010.5416352

Sun, J., Zhu, X., Zhang, C., \& Fang, Y. (2011). Hcpp: Cryptography based secure EHR system for patient privacy and emergency healthcare. In Distributed Computing Systems (ICDCS), 2011 31st International Conference on (pp. 373-382). http://dx.doi.org/10.1109/ICDCS.2011.83

Sun, Y., Wang, N., Guo, X., \& Peng, Z. (2013). Understanding the acceptance of mobile health services: A comparison and integration of alternative models. Journal of Electronic Commerce Research, 14(2), $183-200$.

Taddicken, M. (2014). The 'Privacy Paradox' in the Social Web: The Impact of Privacy Concerns, Individual Characteristics, and the Perceived Social Relevance on Different Forms of Self-Disclosure. Journal of Computer-Mediated Communication, 19(2), 248-273. http://dx.doi.org/10.1111/jcc4.12052

Tang, T. W., \& Chi, W. H. (2005). The Role of Trust in Customer Online Shopping Behavior: Perspective of Technology Acceptance Model. Paper presented at the Proceedings of NAACSOS Conference 2005 Indiana, USA.

Terzis, V., \& Economides, A. A. (2011). Computer based assessment: Gender differences in perceptions and acceptance. Computers in Human Behavior, 27(6), 2108-2122. http://dx.doi.org/10.1016/j.chb.2011.06.005

Thamizhvanan, A., \& Xavier, M. (2013). Determinants of customers' online purchase intention: An empirical study in India. Journal of Indian Business Research, 5(1), 17-32. http://dx.doi.org/10.1108/17554191311303367

The Jordan Times, (2012). from http://jordantimes.com/jordan-remains-medical-tourism-hub-despite-regional-unrest

The Jordan Times. (2014). Retrieved from http://jordantimes.com/zain-jordan-to-introduce-4g-servicesby-year-end

Trobec, R. \& Stanic, U. (2011). Telehealth: A myth or reality? MIPRO: Proceedings of the 34th International Convention, 295-300.

Turner, M., Kitchenham, B., Brereton, P., Charters, S., \& Budgen, D. (2010). Does the technology acceptance model predict actual use? A systematic literature review. Information and Software Technology, 52(5), 463-479. http://dx.doi.org/10.1016/j.infsof.2009.11.005

Van de Watering, M. (2007). The impact of computer technology on the elderly. Retrieved from http://www.few.vu.nl/ rvdwate/HCI_Essay_Marek_van_de_Watering.pdf

Van Slyke, C., Lou, H., Belanger, F., \& Sridhar, V. (2010). The influence of culture on consumer-oriented 
electronic commerce adoption. Journal of Electronic Commerce Research, 11(1), 30-40.

Venkatesh, V., \& Bala, H. (2008). Technology acceptance model 3 and a research agenda on interventions. Decision Sciences, 39(2), 273-315. http://dx.doi.org/10.1111/j.1540-5915.2008.00192.x

Venkatesh, V., \& Davis, F. D. (2000). A theoretical extension of the technology acceptance model: Four longitudinal field $\quad$ studies. Management $\quad$ Science, $\quad 46(2), \quad 186-204$. http://dx.doi.org/10.1287/mnsc.46.2.186.11926

Venkatesh, V., Morris, M. G., Davis, G. B., \& Davis, F. D. (2003). User acceptance of information technology: Towards a unified view. MIS Quarterly, 27(3), 425-478.

Venkatesh, V., Thong, J. Y., \& Xu, X. (2012). Consumer acceptance and use of information technology: extending the unified theory of acceptance and use of technology. MIS Quarterly, 36(1), 157-178.

Verma, C., Nanda, S., Singh, R. K., Singh, R. B., \& Mishra, S. (2011). A review on impacts of genetically modified food on human health. The Open Nutraceuticals Journal, 4, 3-11. http://dx.doi.org/10.2174/1876396001104010003

Wälivaara, B., Andersson, S., Axelsson, K. (2011). General practitioners' reasoning about using mobile distance-spanning technology in home care and in nursing home care. Scandinavian Journal of Caring Sciences, 25(1), 117-125. http://dx.doi.org/10.1111/j.1471-6712.2010.00800.x

Walrave, M., Vanwesenbeeck, I., \& Heirman, W. (2012). Connecting and protecting? Comparing predictors of self-disclosure and privacy settings use between adolescents and adults. Cyberpsychology: Journal of Psychosocial Research on Cyberspace, 6(1). http://dx.doi.org/10.5817/CP2012-1-3

Wang, Y. S., Wu, M. C., \& Wang, H. Y. (2009). Investigating the determinants and age and gender differences in the acceptance of mobile learning. British Journal of Educational Technology, 40(1), 92-118. http://dx.doi.org/10.1111/j.1467-8535.2007.00809.x

Waters, E., Hall, B. J., Armstrong, R., Doyle, J., Pettman, T. L., \& de Silva-Sanigorski, A. (2011). Essential components of public health evidence reviews: Capturing intervention complexity, implementation, economics and equity. Journal of Public Health, 33(3), 462-465. http://dx.doi.org/10.1093/pubmed/fdr064

Whittaker, L., Van Zyl, J., \& Soicher, A. S. (2011). What is the point of the point-of-care? A case study of user resistance to an e-health system. Telemedicine Journal and e-Health: The Official Journal of the American Telemedicine Association, 17(1), 55-61. http://dx.doi.org/10.1089/tmj.2010.0008

Wilkowska, W., \& Ziefle, M. (2011). Perception of privacy and security for acceptance of E-health technologies: Exploratory analysis for diverse user groups. User-Centred-Design of Pervasive Health Applications (UCD-PH'11), held in conjunction with the 5th ICST/IEEE Conference on Pervasive Computing Technologies for Healthcare 2011, pp. 593-600. http://dx.doi.org/10.4108/icst.pervasivehealth.2011.246027

Wilkowska, W., Gaul, S., \& Ziefle, M. (2010). A Small but Significant Difference-The Role of Gender on Acceptance of Medical Assistive Technologies (pp. 82-100). Springer Berlin Heidelberg. http://dx.doi.org/10.1007/978-3-642-16607-5_6

World Health Day. (2014). Non Communicable Diseases, are they becoming Africa's Silent killers? Retrieved from

http://olusegunobasanjofoundation.org/oof_blog/world-health-day-2014-non-communicable-diseases-are-th ey-becoming-africas-silent-killers/\#.VC7jB2eSzIc

Wu, I. L., Li, J. Y., \& Fu, C. Y. (2011). The adoption of mobile healthcare by hospital's professionals: An integrative perspective. Decision Support $\quad$ Systems, http://dx.doi.org/10.1016/j.dss.2011.03.003

Xue, L., Yen, C. C., Chang, L., Chan, H. C., Tai, B. C., Tan, S. B., ... Choolani, M. (2012). An exploratory study of ageing women's perception on access to health informatics via a mobile phone-based intervention. $\begin{array}{lllll}\text { International of Journal } & \text { Medical }\end{array}$ http://dx.doi.org/10.1016/j.ijmedinf.2012.04.008

Yang, K., \& Lee, H. J. (2010). Gender differences in using mobile data services: Utilitarian and hedonic value approaches. Journal of Research in Interactive Marketing, 4(2), 142-156. http://dx.doi.org/10.1108/17505931011051678

Yang, Z., \& Peterson, R. T. (2001). Exploring underlying services quality dimension of internet purchasing: Suggestions from customers' electronic world-of-mouth'. In Proceedings of the 1st International Workshop 
on Management and Innovation of Services, Maastricht, the Netherlands.

Yanping, G., \& Peng, Z. (2012). Impact of perceived reflexive M-commerce on adoption intention in China. African Journal of Business Management, 6(14), 5066-5072. http://dx.doi.org/10.5897/ajbm11.2888

Yao, M. Z., Rice, R. E., \& Wallis, K. (2007). Predicting user concerns about online privacy. Journal of the American Society for Information Science and Technology, 58(5), 710-722. http://dx.doi.org/10.1002/asi.20530

Yaşin, B., \& Özen, H. (2011). Gender Differences in the Use of Internet for Health Information Search. EGE Academic Review, 11(2), 229-240.

Yousafzai, S. Y., Foxall, G. R., \& Pallister, J. G. (2007). Technology acceptance: A meta-analysis of the TAM: Part 1. Journal of Modelling in Management, 2(3), 251-280. http://dx.doi.org/10.1108/17465660710834453

Yousafzai, S., \& Yani-de-Soriano, M. (2012). Understanding customer-specific factors underpinning internet banking adoption. International Journal of Bank Marketing, 30(1), 60-81. http://dx.doi.org/10.1108/02652321211195703

Yu, C. S. (2012). Factors affecting individuals to adopt mobile banking: Empirical evidence from the UTAUT model. Journal of Electronic Commerce Research, 13(2), 104-121.

Yu, P., Li, H., \& Gagnon, M. P. (2009). Health IT acceptance factors in long-term care facilities: A cross-sectional survey. International Journal of Medical Informatics, 78(4), 219-229. http://dx.doi.org/10.1016/j.ijmedinf.2008.07.006

Zhang, J. (2009). Exploring drivers in the adoption of mobile commerce in China. The Journal of American Academy of Business, 15(1), 64-69.

Zhang, J., Mandl, H., \& Wang, E. (2011). The Effect of Vertical-Horizontal Individualism-Collectivism on Acculturation and the Moderating Role of Gender. International Journal of Intercultural Relations, 35, 124-134. http://dx.doi.org/10.1016/j.ijintrel.2010.09.004

Zhang, X., Guo, X., Lai, K. H., Guo, F., \& Li, C. (2014). Understanding Gender Differences in m-Health Adoption: A Modified Theory of Reasoned Action Model. Telemedicine and e-Health, 20(1), 39-46. http://dx.doi.org/10.1089/tmj.2013.0092

Zheng, K., Padman, R., Johnson, M. P., \& Diamond, H. S. (2006). Gender Differences in Adoption and Use of a Healthcare IT Application. In E. M. Trauth (Ed.), Encyclopedia of Gender and Information Technology (pp: 514-522). http://dx.doi.org/10.4018/978-1-59140-815-4.ch080

Zhenyu, C., Huiying, D., Tingjie, L., \& Zhong, H. (2011, August). An Empirical Study of Consumer Adoption on $3 G$ Value-Added Services in China. In 2011 International Conference on Management and Service Science (MASS), pp. 1-4.

Zhou, L., Dai, L., \& Zhang, D. (2007). Online shopping acceptance model-A critical survey of consumer factors in online shopping. Journal of Electronic Commerce Research, 8(1), 41-62.

Ziefle, M., \& Schaar, A. K. (2011). Gender differences in acceptance and attitudes towards an invasive medical stent. Electronic Journal of Health Informatics, 6(2), 13.

Zorotheos, A., \& Kafeza, E. (2009). Users' perceptions on privacy and their intention to transact online: A study on Greek internet users. Direct Marketing: An International Journal, 3(2), 139-153. http://dx.doi.org/10.1108/17505930910964795

Zukowski, T., \& Brown, I. (2007, October). Examining the influence of demographic factors on internet users' information privacy concerns. In Proceedings of the 2007 annual research conference of the South African institute of computer scientists and information technologists on IT research in developing countries (pp. 197-204). ACM. http://dx.doi.org/10.1145/1292491.1292514

Zulman, D. M., Kirch, M., Zheng, K., \& An, L. C. (2011). Trust in the internet as a health resource among older adults: Analysis of data from a nationally representative survey. Journal of Medical Internet Research, 13(1). http://dx.doi.org/10.2196/jmir.1552 


\section{Appendix A}

Survey questionnaire, mean, std. deviation and factor loadings

\begin{tabular}{|c|c|c|c|c|}
\hline Nos. & Social Influence & Mean & Std. Deviation & Loading \\
\hline 1 & $\begin{array}{l}\text { People who affect my behavior believe that I should use the mobile phone to perform } \\
\text { m-healthcare behaviors. }\end{array}$ & 3.34 & 1.090 & 0.765 \\
\hline 2 & $\begin{array}{l}\text { People who are important to me believe that I should use the mobile phone to perform } \\
\text { m-healthcare behaviors. }\end{array}$ & 3.41 & 1.073 & 0.766 \\
\hline 3 & $\begin{array}{l}\text { The senior management of Ministry of Health has been helpful in the use of the mobile } \\
\text { phone to perform m-healthcare behaviors. }\end{array}$ & 3.06 & 1.250 & 0.843 \\
\hline 4 & $\begin{array}{l}\text { In general, the Ministry of Health supports the use of mobile phone to perform } \\
\text { m-healthcare behaviors through distributing bulletins and providing free education for } \\
\text { citizens. }\end{array}$ & 3.02 & 1.290 & 0.757 \\
\hline \multicolumn{2}{|r|}{ 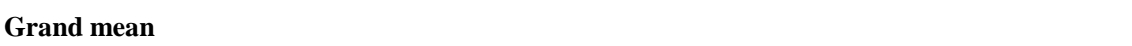 } & \multicolumn{2}{|c|}{3.21 (Medium) } & \\
\hline Nos. & Trust & Mean & Std. Deviation & Loading \\
\hline 1 & I overall trust the services that are offered by mobile phone. & 3.14 & 1.038 & 0.728 \\
\hline 2 & $\begin{array}{l}\text { I expected that using the mobile phone to perform } \mathrm{m} \text {-healthcare behaviors will be available } \\
\text { for use without interruption of service. }\end{array}$ & 3.29 & 1.127 & 0.831 \\
\hline 4 & $\begin{array}{l}\text { I thought that using mobile phone to perform m-healthcare behaviors has the capability to } \\
\text { provide a desired level of service in adverse or hostile conditions (e.g., natural disasters). }\end{array}$ & 3.52 & 1.051 & 0.657 \\
\hline 5 & $\begin{array}{l}\text { I highly trust the technology such as the network provided by Jordanian mobile operators to } \\
\text { perform m-healthcare behaviors. }\end{array}$ & 3.43 & 1.147 & 0.800 \\
\hline \multicolumn{2}{|c|}{ Grand mean } & \multicolumn{2}{|c|}{3.35 (Medium) } & \\
\hline Nos. & Security/Privacy & Mean & Std. Deviation & Loading \\
\hline 1 & Using the mobile phone to perform $\mathrm{m}$-healthcare behaviors is secure. & 3.24 & 1.058 & 0.808 \\
\hline 2 & $\begin{array}{l}\text { Using the mobile phone to perform m-healthcare behaviors does not disclose my private } \\
\text { information. }\end{array}$ & 3.09 & 1.206 & 0.820 \\
\hline 3 & $\begin{array}{l}\text { Government laws, regulations and legislations are important to adopt and perform } \\
\text { m-healthcare behaviors. }\end{array}$ & 3.10 & 1.229 & 0.799 \\
\hline \multicolumn{2}{|c|}{ Grand mean } & \multicolumn{2}{|c|}{3.14 (Medium) } & \\
\hline Nos. & Cost & Mean & Std. Deviation & Loading \\
\hline 1 & It would cost a lot to use m-healthcare technology. & 2.97 & 1.224 & 0.832 \\
\hline 2 & $\begin{array}{l}\text { There are financial barriers for having the needed mobile-based technologies to adopt and } \\
\text { use m-healthcare technology. }\end{array}$ & 2.93 & 1.148 & 0.755 \\
\hline 3 & $\begin{array}{l}\text { I expected that the cost of services provided by the national network operators to perform } \\
\text { m-healthcare behaviors would be expensive. }\end{array}$ & 3.06 & 1.179 & 0.812 \\
\hline \multicolumn{2}{|c|}{ Grand mean } & \multicolumn{2}{|c|}{2.98 (Low) } & \\
\hline Nos. & Perceived Usefulness & Mean & Std. Deviation & Loading \\
\hline 1 & Using mobile phone would improve my performance in conducting m-healthcare behaviors. & 3.97 & 2.767 & 0.813 \\
\hline 2 & Using mobile phone would make it easier for me to perform m-healthcare behaviors. & 3.99 & 0.769 & 0.778 \\
\hline 3 & I would find the mobile phone useful in performing $\mathrm{m}$-healthcare behaviors. & 4.42 & 3.756 & 0.864 \\
\hline \multicolumn{2}{|c|}{ Grand mean } & \multicolumn{2}{|c|}{4.13 (High) } & \\
\hline Nos. & Perceived Ease of Use & Mean & Std. Deviation & Loading \\
\hline 1 & Learning to use mobile phone to perform m-healthcare behaviors is easy for me. & 3.96 & 0.890 & 0.806 \\
\hline 2 & $\begin{array}{l}\text { It would be easy for me to obtain what I need by using mobile phone to perform } \\
\text { m-healthcare behaviors. }\end{array}$ & 3.80 & 0.933 & 0.851 \\
\hline 3 & $\begin{array}{l}\text { My interaction with a mobile phone to perform m-healthcare behaviors procedure would be } \\
\text { clear and understandable. }\end{array}$ & 3.92 & 0.909 & 0.774 \\
\hline 4 & I would find mobile phone to perform m-healthcare behaviors easy to use. & 3.91 & 0.908 & 0.779 \\
\hline \multicolumn{2}{|c|}{ Grand mean } & \multicolumn{2}{|c|}{3.90 (High) } & \\
\hline Nos. & Behavioral Intention to Use & Mean & Std. Deviation & Loading \\
\hline 1 & I intend to use the mobile phone to perform m-healthcare behaviors frequently. & 3.88 & 0.956 & 0.870 \\
\hline 2 & $\begin{array}{l}\text { I predict that I should use the mobile phone to perform m-healthcare behaviors in the } \\
\text { future. }\end{array}$ & 4.00 & 0.849 & 0.857 \\
\hline 3 & It is likely that I will use the mobile phone to perform m-healthcare behaviors in the future. & 4.04 & 0.910 & 0.878 \\
\hline \multicolumn{2}{|c|}{ Grand mean } & \multicolumn{2}{|c|}{3.97 (High) } & \\
\hline
\end{tabular}




\section{Copyrights}

Copyright for this article is retained by the author(s), with first publication rights granted to the journal.

This is an open-access article distributed under the terms and conditions of the Creative Commons Attribution license (http://creativecommons.org/licenses/by/3.0/). 